\title{
CATEGORY ASSIGNMENT AND RELATEDNESS IN THE GROUP IDEATION PROCESS
}

by

\author{
JONALI BARUAH
}

Presented to the Faculty of the Graduate School of The University of Texas at Arlington in Partial Fulfillment of the Requirements for the degree of

\section{DOCTOR OF PHILOSOPHY}

\section{UNIVERSITY OF TEXAS AT ARLINGTON}

August 2008 
Copyright (C) by Jonali Baruah 2008

All Rights Reserved 


\section{DEDICATION}

This manuscript is whole-heartedly dedicated to my parents, Jyotsna and Pawan Baruah, for their love, support and inspiration throughout my life. 


\section{ACKNOWLEDGEMENTS}

I wish to express my sincere appreciation to my mentor Dr. Paul Paulus for his support during the course of my graduate career. Dr. Paulus had an immense impact on my professional development. He provided me with challenging opportunities and an important role model. I would not be where I am today if Dr. Paulus did not encourage me, inspire me and constructively criticize me. I am grateful for having had the opportunity to work with him. I also offer my deep appreciation to Dr. Vincent Brown for all his thoughtful advice and suggestions in the development of this dissertation. Thanks are due to the committee members, Drs. Levine, Kenworthy and Mellgren for their interest and valuable suggestions. I would like to thank my friends Toshi Nakui, Ada Woo, Denise Arellano, and Kim McConnell for their inspiration and encouragement throughout my years in the graduate school. Vanessa Garcia and Ana Gonzalez were immensely valuable throughout the various phases of my dissertation. They coded and categorized the data with amazing speed and accuracy. I would like to thank my parents Pawan and Jyotsna Baruah for always believing in me and willing to help me in any way possible to achieve my goals. Thanks are due to my son Neel and daughter Nishtha for understanding how busy their mummy is. I owe a special and deep debt of gratitude to my husband, Pankaj Panging, for his support and patience. Finally, I thank God for all His blessings.

May 29, 2008 


\begin{abstract}
CATEGORY ASSIGNMENT AND RELATEDNESS IN THE GROUP IDEATION PROCESS

Jonali Baruah, $\mathrm{PhD}$.

The University of Texas at Arlington, 2008
\end{abstract}

Supervising Professor: Paul Paulus

Although many studies have investigated the effects of task related diversity on group performance, little empirical attention has been paid to the effect of the degree of relatedness of these tasks on the group ideation process. The present study provided a comprehensive test of the effects of task (category) assignment and relatedness on creativity of the interactive and the nominal groups in electronic brainstorming paradigm. A major area that has not been explored in the brainstorming literature is how groups perform when each member is assigned a unique category compared with having all the members jointly assigned with common categories. The current study investigated whether the assignment of categories that are high or low in relatedness will lead to higher quantity, flexibility, originality, clustering of the ideas and perceived enjoyment in an electronic brainstorming task. The participants were assigned with categories related to a broader problem. The assigned categories were either high or low in their degree of relatedness. 
300 undergraduate students from the introduction to psychology classes at the University of Texas at Arlington participated in the experiment. The design was a 2(category relatedness) x 2(category assignment) x 2(type of group) between groups design. The interactive groups surveyed fewer categories and exhibited high clustering compared to the nominal groups. Moreover, the clustering exhibited by interactive groups was magnified by the joint assignment condition. The groups jointly assigned with three categories generated higher quantity of ideas, explored more categories and exhibited higher clustering than the groups who were assigned with individual categories. The post-experimental affect questionnaire revealed that the interactive groups jointly assigned with three categories enjoyed the brainstorming session the most. In terms of category relatedness, groups assigned with categories of low relatedness surveyed more categories than those assigned with categories of high relatedness. The results of this study enhance our understanding of the productivity and the divergent and convergent tendencies of groups related to different types of task assignment and have implications for models of the group creative process (Nijstad \& Stroebe, 2006; Paulus \& Brown, 2007). 


\section{TABLE OF CONTENTS}

ACKNOWLEDGEMENTS...........................................................

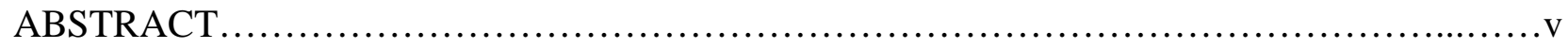

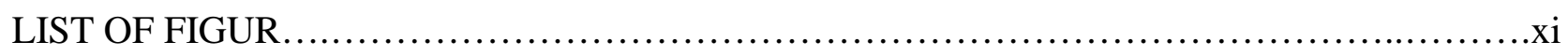

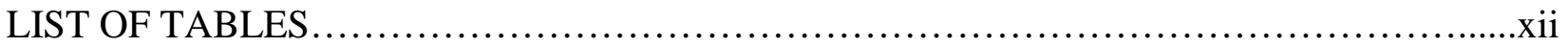

Chapter

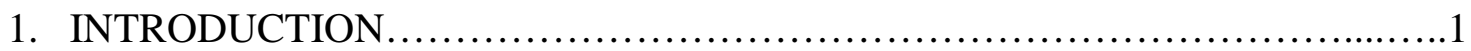

1.1 Diversity in members' perspective...................................5

1.2 Task decomposition in brainstorming research.........................6

1.3 Task decomposition and convergent-divergent orientation...................8

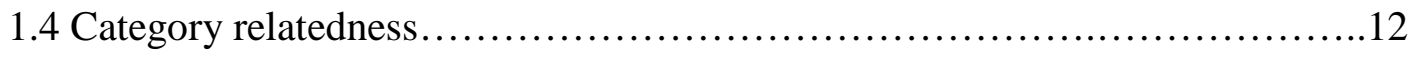

1.5 Interactive versus nominal paradigm.................................... 15

2. STUDY I...........................................................

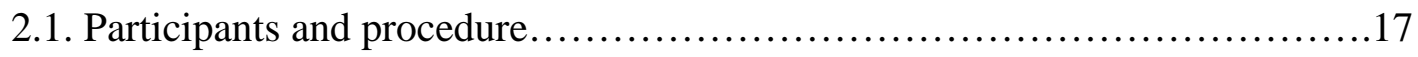

2.2 Results and discussion............................................ 19

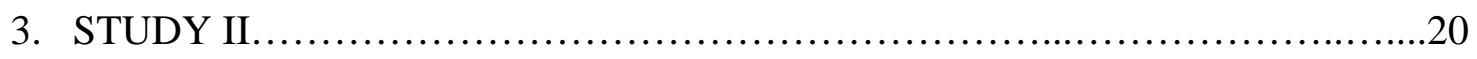

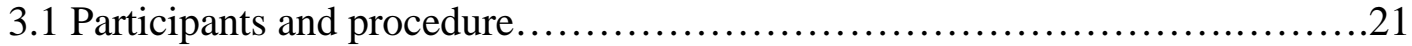




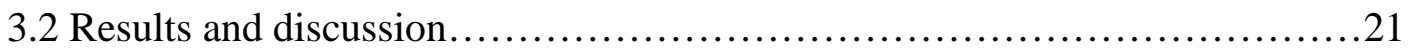

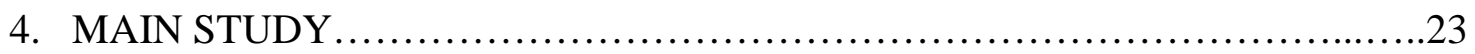

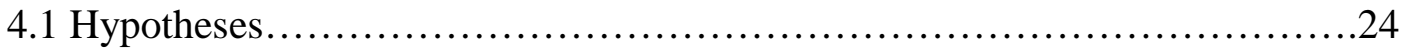

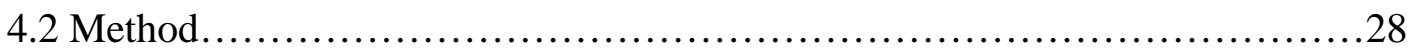

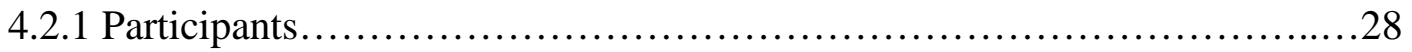

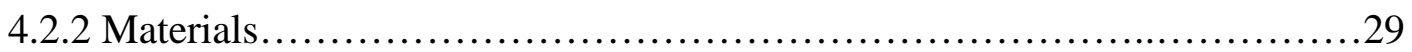

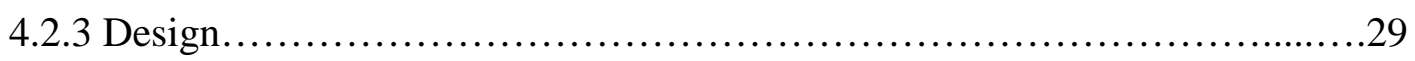

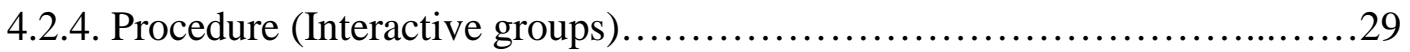

4.2.5 Procedure (Nominal groups) ........................................... 31

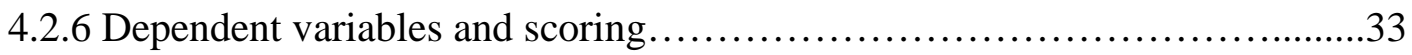

4.2.7 Forming Categories................................................... 34

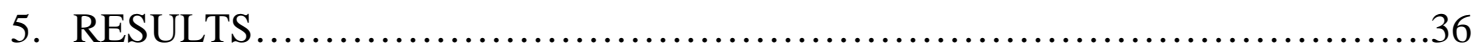

5.1 Manipulation checks and preliminary analyses.............................36

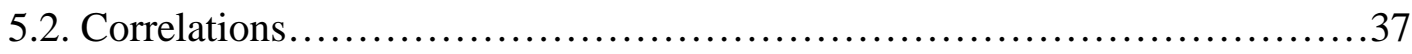

5.3. Group performance data.................................................. 42

5.3 .1 Quantity....................................................... 43

5.3.1.1 Quantity - with respect to the control groups.................46

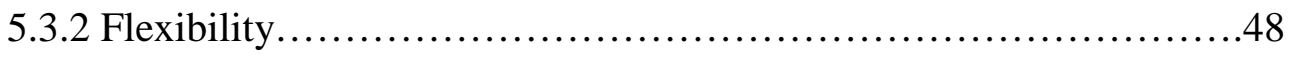

5.3.2.1 Flexibility - with respect to the control group..............50

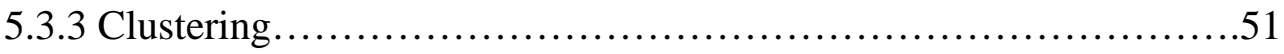

5.3.3.1 Clustering - with respect to the control group...............55

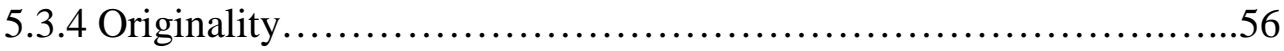

5.3.4.1 Originality-with respect to the control group................58 
5.3.5.1 Perceived enjoyment -with respect to the control group.....62

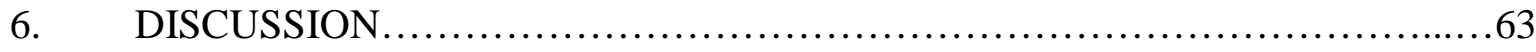

6.1 Quantity, quality and convergence.....................................64

6.2 Effects of category assignment.........................................66

6.3 Effects of category relatedness...........................................68

Appendix

A. BACKGROUND QUESTIONNAIRE ....................................73

B. RULES FOR THE INTERACTIVE GROUPS...................................75

C. RULES FOR THE NOMINAL GROUPS................................... 77

D. INSTRUCTIONS FOR CATEGORY ASSIGNMENT (INTERACTIVE) .........79

E. INSTRUCTIONS FOR CATEGORY ASSIGNMENT (NOMINAL)..............81

F. INSTRUCTIONS FOR INDIVIDUAL ASSIGNMENT (INTERACTIVE).........83

G. INSTRUCTIONS FOR JOINT ASSIGNMENT (INTERACTIVE)..................85

H. INSTRUCTIONS FOR INDIVIDUAL ASSIGNMENT (NOMINAL) ..............87

I. INSTRUCTIONS FOR JOINT ASSIGNMENT (NOMINAL)....................89

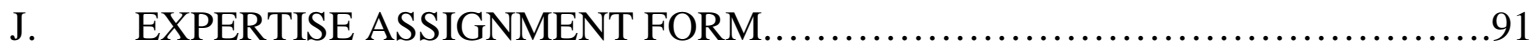

K. POST EXPERIMENT QUESTIONNAIRE (INTERACTIVE GROUPS).............93

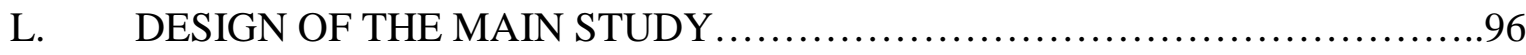

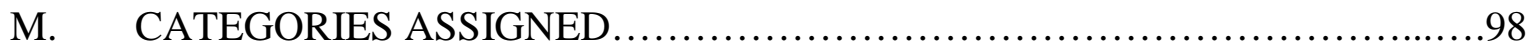

N. CATEGORIES USED FOR RELATEDNESS RATINGS .......................100

O. POST EXPERIMENTAL QUESTIONNAIRE (NOMINAL GROUPS) ............102

P. CATEGORIES USED FOR IDEA RATINGS ...............................104 
REFERENCES ..........................................................................

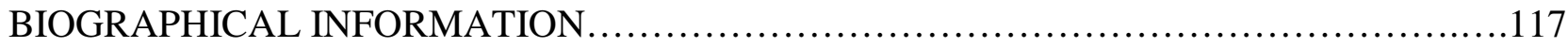




\section{LIST OF FIGURES}

Figure

Page

1. Quantity of ideas for interactive experimental and interactive control group as a function of type of assignment

2. Average flexibility for interactive experimental and interactive control groups as a function of category relatedness.

3. Clustering of ideas as a function of groups and category assignment $\ldots \ldots \ldots \ldots \ldots \ldots \ldots \ldots . .52$

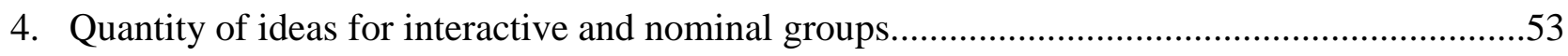

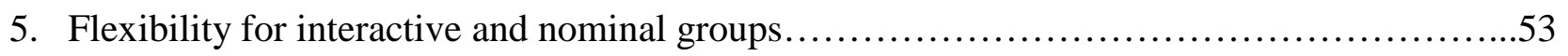

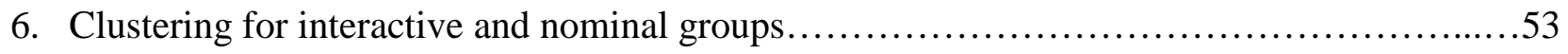

7. Originality of ideas for interactive and nominal groups...............................54

8. Perceived enjoyment for interactive and nominal groups.............................54

9. Average clustering for interactive experimental and interactive control groups

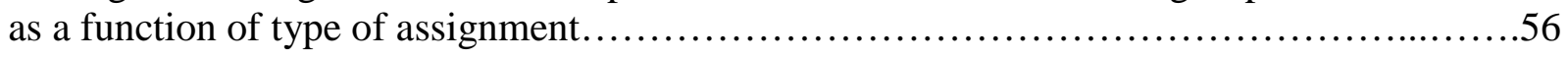

10. Average originality of ideas as a function of category relatedness, assignment

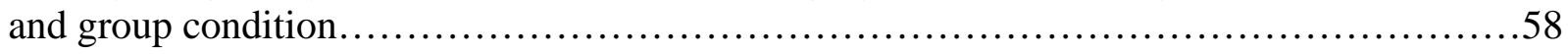

11. Average originality for experimental interactive and nominal with control..................59

12. Perceived enjoyment as a function of type of category relatedness and assignment..........61

13. Perceived enjoyment as a function of type of category assignment and group condition 


\section{LIST OF TABLES}

Tables

Page

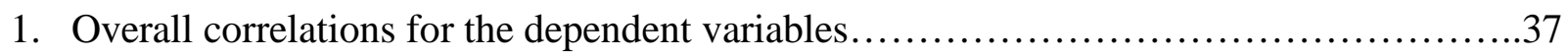

2. Correlations of dependent variables for interactive groups only.......................39

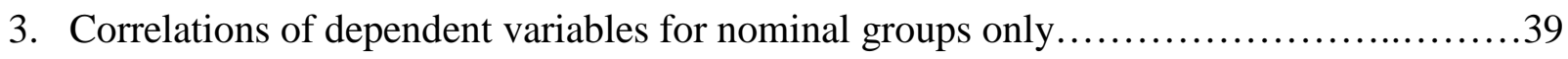

4. Correlations of dependent variables for joint assignment only $\ldots \ldots \ldots \ldots \ldots \ldots \ldots \ldots \ldots . \ldots 40$

5. Correlations of dependent variables for individual assignment only $\ldots \ldots \ldots \ldots \ldots \ldots \ldots \ldots 40$

6. Correlations of dependent variables for high-related categories only..................41

7. Correlations of dependent variables for low-related categories only..................41

8. Multivariate Tests........................................................... 42

9. Univariate tests for nominal and interactive groups combined........................44

10. Quantity of ideas generated as a function of type of assignment

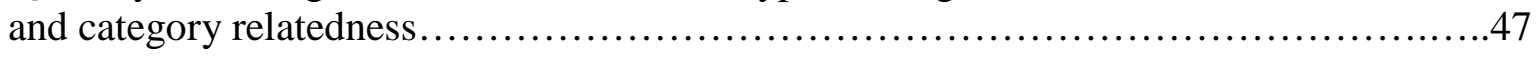

11. Average flexibility as a function of type of assignment and category relatedness..........50

12. Average clustering as a function of type of assignment and category relatedness..........55

13. Mean originality as a function of type of assignment and category relatedness...........57

14. Mean perceived enjoyment as a function of type of assignment and category

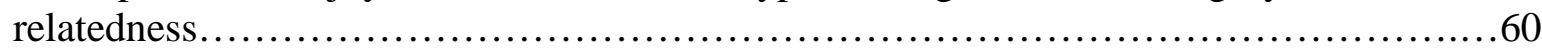




\section{CHAPTER 1}

\section{INTRODUCTION}

Groups hold a prominent position in our society. Group interaction is often required to develop new ideas for the delivery of products and services. The nature of group interactions may vary from face-to-face to video conferencing to teleconferencing to internet chat groups. With the advent of outsourcing, the interaction between dispersed group members is becoming more and more crucial to organizations. Many problems require collaboration at a team level with the members coming from different academic disciplines or different divisions of the organization. This type of collaboration may pose many challenges when communication is needed across the geographical distances that often separate such experts. Brainstorming towards solution of a problem is one such method that often requires collaboration in groups.

Of all the techniques, brainstorming is the most basic and widely used idea generation technique (Hender, Dean, Rodgers \& Nunamaker, 2002). Most of the earlier studies in brainstorming research have focused on the effectiveness of the brainstorming groups in a faceto-face paradigm. One of the most common findings in this area is that face-to-face groups generate fewer ideas than nominal groups, which are composed of a comparable number of individual brainstormers (Diehl \& Stroebe, 1987; Mullen, Johnson \& Salas, 1991). Face-to-face groups are also found to have some inherent problems such as consensus seeking (Janis, 1972), biased information sharing (Stasser \& Titus, 1985), and social matching of low performance 
level (Paulus \& Dzindolet, 1993). Many researchers have tried to improve the performance of face-to-face groups through training and facilitation (Anson, Bostrom \& Wynne, 1995; Baruah \& Paulus, 2008; Kramer, Fleming, \& Mannis, 2001; Offner, Kramer, \& Winter, 1996). These procedures have improved the process gains in groups. However, these processes are expensive and time consuming.

One way of enhancing the performance of a brainstorming group is the division of labor or assignment of different parts of the task to different members of the group. Organizations often require the division of responsibility or assignment of different parts of the task to different members of the group to reduce the cognitive or the physical burden of the responsibilities. Division of the task by assigning roles strengthens positive interdependence in cooperative learning groups, which leads to high group performance (Johnson \& Johnson, 1989, 1999). According to Johnson and Johnson (1989), when group members have complementary roles and responsibilities that are interconnected, it contributes to the accomplishment of the task. The same positive effect of task assignment was replicated in the study of Beck-Jones (2004).

Research in the area of transactive memory has manipulated the member's areas of expertise by assigning different categories or information to the ad hoc groups. Such studies have found that groups develop a mutual understanding of "who knows what" which helps them to perform better on group recall tasks (Hollingshead, 1998a, 1998b; Wegner, 1987) as well as certain motor tasks (Moreland, Argote, \& Krishnan, 1996). Similarly, Stasser and Titus (1985) manipulated group member's areas of expertise in terms of category assignment and found that groups shared more unshared information when the members had diverse areas of expertise. Studies in the area of brainstorming have revealed that the task decomposition leads to increased 
ideation in groups (Coskun, Paulus, Brown \& Sherwood, 2000; Paulus, Nakui \& Putman, 2006). However, the task decomposition in brainstorming research did not involve assignment of subtasks to individual members. Such task decomposition through division of a task into subtasks and their assignment to individuals in the group should enhance the performance of brainstorming groups because it increases accountability (Hollingshead, 1998a) and motivation of the members to work harder due to their individual responsibilities (Harkins \& Petty, 1982).

Although a wealth of studies has investigated the effects of diverse areas of expertise on group performance, there is a dearth of studies examining the degree of relevance or relatedness of these areas on group performance. For example, will a diverse group having expertise in highly related areas (such as a psychology major, a sociology major, and a philosophy major) perform better than a group of participants having expertise in unrelated or low relatedness areas (say a biology major, a philosophy major and a music major)? Studies have found that combination and reorganization of low related information can lead to higher average originality of the solutions in individual participants (Mobley, Doares, \& Mumford, 1992). However, no studies in the area of brainstorming have investigated whether a combination of different perspectives that are high or low in relatedness will lead to higher quality of the ideas generated in groups.

A consistent finding in brainstorming research is that the face-to-face groups generate fewer ideas than computer-mediated groups of equal size (e.g., Gallupe, Bastianutti, \& Cooper, 1991). The major reasons for this superiority of computer mediated communication, especially electronic brainstorming (EBS henceforth), are 1) elimination of production blocking (Gallupe, Cooper, Grise \& Bastianutti, 1994) and 2) cognitive stimulation from reading the ideas of others 
(Connolly, Routhieaux, \& Schneider, 1993; Dennis \& Williams, 2003). Production blocking is eliminated because the members can generate ideas simultaneously without waiting for their turns to come. Cognitive stimulation occurs when idea of one member may cue another idea in another member's mind.

Some researchers have suggested that avoiding and eliminating the production losses in groups is a more effective way of enhancing productivity than reinforcing the process gains in groups (Amabile, 1996; Pinsonneault, Barki, Gallupe \& Hoppen, 1999). Therefore, one way of avoiding such process losses in groups is the use of EBS. Studies have demonstrated that idea generation software packages can help individuals generate more creative alternatives to problems (MacCrimmon \& Wagner, 1994) and help individuals see the problem differently, resulting in diverse ideas (Garfield, Taylor, Dennis, \& Satzinger, 2001).

The current research seeks to investigate group performance on an idea generation task when the members are diverse in terms of their assigned topics in a computer mediated communication paradigm. Because diversity in terms of member's perspectives is a major focus of the current research, an overview of the results of the diversity literature in terms of member's perspectives will be presented. Second, the review will more specifically discuss brainstorming research involving group task assignment and underlying cognitive processes. Third, because the second variable that will be explored is the degree of relatedness of the assigned topics, an overview of literature relevant to this issue will be provided. The third variable that will be explored in this study is the group condition (interactive and nominal groups). Therefore, a review of literature related to group condition will be elaborated. This will be followed by the 
description of the two pilot studies that were done to test the manipulation of the areas of expertise. Finally, the main study will be presented.

\section{$\underline{1.1 \text { Diversity in members' perspective }}$}

Previous studies have suggested that variety in perspectives and experiences in groups contributes to the production of higher-quality ideas (Bental \& Jackson, 1989). Ancona and Caldwell (1992) found that as the functional expertise of the members increased there was an increase in external communication with individuals outside of the organization. This in turn helped bring divergent perspectives in the group and increased the knowledge available to the group. Diverse skills and interests were also found to be beneficial to research scientists' creativity (Dunbar, 1997; Pelz \& Andrews, 1966). Wanous and Youtz (1986) found that diversity in opinions led to better quality of decisions. In support of the above argument Bowers, Pharmer and Salas (2000) found that when the task is complex and information is limited, heterogeneity in team can lead to focusing on wider range of options to perform the task effectively.

Research in the area of transactive memory also reveals the importance of different areas of expertise of the members on group performance (Hollingshead, 1998b, 2001; Littlepage, Robison \& Reddington, 1997; Stewart, Wittenbaum \& Stasser, 1995). According to this concept, the quality of group performance may depend on whether the group can utilize the differential knowledge of its members to develop an effective transactive memory system. The group members can assign separate responsibility or information to each member based on their expertise. Thus, the cognitive burden of each individual member is reduced, yet a large pool of information is available to each member (Wegner, 1995). Similarly, task separation has been 
investigated in the area of brainstorming research in the form of presentation of a problem in parts to the groups.

\section{$\underline{1.2}$ Task decomposition in brainstorming research}

The importance of breaking a problem into different components to make the brainstorming more effective was suggested by Osborn (1957). Dennis, Aronson, Heninger and Walker (1996) found that presenting the groups with a problem decomposed into categories in an EBS paradigm led to improved performance (sixty percent more ideas) compared with the groups for whom the problem was presented as a whole. To further understand this effect of task decomposition, Coskun, et al. (2000) looked at the effects of task decomposition in nominal and face-to-face groups. The participants were presented with categories in either a simultaneous or a sequential problem presentation paradigm. They found an improved performance in the sequential paradigm compared to the simultaneous paradigm in both interactive and nominal groups.

The research related to task decomposition in the area of individual and group brainstorming has thus explored the effects of order of presentation of tasks (Coskun et al., 2000; Dennis et al., 1996) in interactive and nominal group paradigm. However, a major area that has not been explored is how groups perform when a task is decomposed into discreet parts and each part is assigned to a member of the group. This type of task decomposition should influence the group ideation process both socially and cognitively.

From the perspective of the social loafing literature, Harkins and Petty (1982) found that interactive groups were motivated to perform better on a brainstorming task when each individual had a unique part to contribute. Additionally, they found that if everyone worked on the same task, subjects loafed, but when each subject had his or her own unique task, the subjects 
did not loaf even though each member knew that he/she was unidentifiable in the task. Assigning a unique part of a task to each member and making the members aware of each other's unique knowledge should lead to the generation of more diverse ideas. Studies in the area of group dynamics have found that small groups perform better than the best person in the group if the problem has several parts and members have different thinking styles and knowledge. Such assignment of unique parts to the individuals in the group should also lead to divergent thinking in brainstorming groups. Thus, each person can present unique approaches to the problem (Maier, 1967). Johnson, Johnson and Stanne (1989) found that cooperative learning triads performed better if the group members had to depend on each other for the outcome and needed resources. Finally, Stewart, Billings, and Stasser (1998) found that assignment of categories led to increased accountability which improved performance in a hidden profile task.

Several lines of research suggest the cognitive impact of task decomposition. Studies in word recall tasks have found that task decomposition leads individuals to pay equal attention to all the assigned categories (Armstrong, Denniston \& Gordon, 1975; Pitz, Sachs \& Heerboth, 1980). Moreover, it reduces the cognitive overload since each member is assigned with a unique part of the task. Basden, Basden, Bryner and Thomas III (1997) assigned three-member interactive or nominal groups with six categories to recall. Half of the participants were assigned with six categories to recall together in group and the other half were assigned with two categories per person in a group to recall. They found that when all group members recalled items from all six categories one person's retrieval of an idea prematurely aborts the retrieval strategy of another person in the group (collaborative inhibition). They reported that collaborative inhibition occurred in interactive paradigm because "participants' strategy for retrieving ideas from a category is made obsolete by the premature retrieval of ideas by other 
members of the groups". For groups in which each member was instructed to recall items from two of the six categories the collaborative inhibition was reduced. Weldon and Bellinger (1997) also reported similar inhibitory processes in a collaborative group recall paradigm. In their study they asked the groups to recall a story. They argued that because the organizational structure of a story is relatively complex and rigid, it might take considerable cognitive effort to retrieve and maintain one's own representation while monitoring the story development in the group. Furthermore, an individual may not want to disturb the flow of the story by asking the group to pause and add his or her part to it. In the similar vein, in a brainstorming paradigm when the participants have to generate ideas in groups from a common set of categories, there could be a possibility of such collaborative inhibition. The recall of one member's idea may disrupt the train of thoughts of the other members in the group (Nijstad \& Stroebe, 2006). However, individual assignment of parts of the problem will minimize such effects, as each member will have a unique part from which to generate ideas.

\section{$\underline{1.3 \text { Task decomposition and convergent-divergent orientation }}$}

Brainstorming is generally considered a divergent thinking task since the brainstormers do not have a specific focus towards solving a problem. On the other hand, decision making is considered a convergent thinking task since the members are focused on the solution of a specific problem (Larey \& Paulus, 1999). However, within a brainstorming task there can be both divergent and convergent thinking tendencies. Researchers have examined the divergent and convergent tendencies in different ways. Brown, Tumeo, Larey and Paulus (1998) measured divergence in terms of the participant's number of shifts among the categories of ideas in a session. In contrast, convergence was measured by the number of repetitions of categories in a brainstorming session. Nijstad and Stroebe (2006) defined divergence as diversity (number of 
categories surveyed at least once) and convergence as clustering (repetition of ideas in a category). Larey and Paulus (1999) on the other hand defined brainstorming task as a divergent task and evaluation of ideas as a convergent task. Finally, a fourth group of researchers contextually generated the divergent and convergent thinkers by means of task instruction (Coskun, 2005; Eisenberger \& Armeli, 1997). Divergence in the current research is measured in two ways, in terms of repetition of an idea from the same category corrected for chance (convergent orientation) (Roenker, Thompson \& Brown, 1973) and the number of categories surveyed at least once (flexibility).

Different areas of psychological research have consistently found that interactive groups have a convergent tendency. Evidence indicates that decomposition of a task into multiple components or categories decreases the tendency of brainstorming groups to converge on a small number of dominant categories (Bouchard, Drauden, \& Barsaloux, 1974; Larey \& Paulus, 1999; Taylor, Berry, \& Block, 1958; Vroom, Grant, \& Cotton, 1969). In the brainstorming paradigm, studies have found that groups tend to explore fewer categories of ideas (Brown, Tumeo, Larey, \& Paulus, 1998; Lamm \& Trommsdorff, 1973; Larey \& Paulus, 1999; Paulus \& Brown, 2007) and to scan only a small number of the ideas from available cognitive categories (Brown et al., 1998; Connolly, Routhieaux, \& Schneider, 1993; Gettys, Pliske, Manning, \& Casey, 1987). In the hidden profile paradigm Stasser and Titus (1985) and Fisher (1980) found that people in groups do not engage in extensive consideration of information. They tend to narrow their focus trying to gain consensus. This consensus seeking nature of groups has been highlighted by the groupthink perspective of Janis (1972). From the cognitive psychological perspective, studies have demonstrated that participants are more likely to remain in the same category than to make shifts from one category to another during the brainstorming session (Brown et al., 1998; Nijstad 
\& Stroebe, 2006). Such a tendency was also confirmed by the research findings of Larey and Paulus (1999). They found that interactive groups not only tend to explore fewer categories of ideas, but they also tend to get fixated to a particular topic. They defined this consensus seeking nature of groups in the context of brainstorming as the amount of time spent by the interactive groups talking about one category of ideas. Bouchard et al. (1974) speculated that if interactive groups become fixated in a category for too long, they tend to generate more ideas within the category and fewer ideas across different categories. They also reported that when groups converge on a few categories they tend to delve into them more deeply and come up with ideas that are more original.

Previous studies have found an association between convergence/divergence and quality and quantity of ideas generated. The support for this suggestion comes from the evidence that divergent thinkers offered more diverse ideas or opinions (Engelmann \& Gettys, 1985; Nemeth \& Nemeth-Brown, 2003) and scanned a large number of categories (Brown et al., 1998; Larey \& Paulus, 1999). The association between divergence and quantity of ideas has been suggested by the associative-memory-model developed by Brown et al. (1998) (also see Paulus \& Brown, 2007). The model suggests that when an idea is generated, it actives the other associated ideas. These associations spread to other ideas in the same category or another category. This situation is more favorable in the diverse category condition since the activation of these diverse categories will enhance the production of a large number of ideas from diverse categories, leading to divergent thinking. Thus, the tendency of divergent thinking should be positively associated with the quantity of ideas generated.

In contrast to the above findings, Nijstad, Stroebe and Lodewijkx (2002) found that convergent thinking (within category fluency) was positively associated with productivity. 
Nijstad and Diehl (2006) explained the above phenomenon based on their SIAM (Search for Ideas in Associative Memory) model. The idea from one semantic category should often be followed by an idea from the same semantic category. However, when a category is changed a new search of memory is necessary. This change takes some time compared to generating ideas from the same category. Therefore, because the category switching process is slower, it will lead to fewer ideas being generated within the same time interval (Nijstad \& Stroebe, 2006).

Although the two models (associative memory model and SIAM) make predictions about the quantity of ideas, they do not directly address the quality of ideas. They may assume that quantity leads to quality since they are highly correlated (e.g., Stroebe \& Diehl, 1994). However, a few recent studies (Baruah \& Paulus, 2008; Rietzschel, Nijstad, \& Stroebe, 2007) found that quantity was not associated with average quality of ideas generated (see also, Diehl \& Stroebe, 1987). Therefore, even though between-category fluency may lead to higher quantity of ideas, it may not lead to ideas of higher average originality since the categories are explored superficially (Larey \& Paulus, 1999). However in the case of convergent thinking (within-category fluency), some categories will be explored more in depth, and this should subsequently lead to generation of more unique ideas (Bouchard et al., 1974; Ziegler, Diehl \& Zijlstra, 2000). Ziegler et al. (2000) found that four-person EBS groups that could share ideas surveyed fewer categories of ideas than did the groups that could not share ideas (similar to nominal paradigm). However, the idea categories were surveyed to a greater depth in the former case.

From the above review of literature, it is clear that groups tend towards convergence. Convergence can also influence the ideation process. Such convergent tendency was also found in electronic brainstorming groups (Ziegler et al., 2000). One reason why group members tend to converge could be that they find some common ground and feel comfortable discussing the areas 
of commonality. Similarity attraction theory ( Byrne, 1961, 1971) posits that people gain approval by imitating others. If similarity attraction theory holds true for computer-mediated groups, the possible basis of similarity could be the knowledge, values or attitudes shared in the discussion. Therefore, the degree of overlap or similarity in knowledge base or assigned expertise in the groups should be an important predictor of the convergent tendency in groups. Hence, the second variable that is predicted to be a significant contributor in the group cognitive processes is the degree of relatedness of the assigned categories.

\section{$\underline{1.4 \text { Category relatedness }}$}

The research in the area of combination and reorganization of information has commonly manipulated the relatedness and unrelatedness of the information provided. The concept of combination and reorganization refers to the process of combining and reorganizing existing knowledge structures or conceptual categories (Mobley et al., 1992). A series of studies have been done by Mumford and his colleagues on the combination and reorganization of categories with respect to the degree of relatedness of the information provided (Mumford \& Gustafson, 1988; Mobley, et al., 1992). The task they used was presentation of a series of categoryexemplars to the individual participants. For example, the category "furniture" has several exemplars such as chair, table, stool and couch. Similarly, the category "bird" has exemplars such as robin, sparrow, crow and owl. The participants were provided with exemplars of several categories (not the categories themselves) and were asked to generate and label new categories capable of accounting for the original exemplars.

Mobley et al. (1992) presented the participants with four exemplars of three standard categories. They manipulated the relatedness of idea categories (high or low) and found that the low related categories resulted in higher average originality of the solution whereas similar 
categories led to higher quality solutions. They defined originality as "a novel response that went beyond the manifest stimulus context". Quality on the other hand was defined as the categories or exemplars that were appropriate with respect to the given categories of exemplars. This is equivalent to feasibility of ideas in brainstorming research. The second manipulation in their study was the instruction for problem construction. In a restricted problem construction condition the participants were instructed to combine only two of the three given standard categories, whereas in an unrestricted problem construction condition the participants were to use all three categories in formulating new categories. The rationale behind this manipulation was that restriction of selection strategies would inhibit the problem construction and diminish the quality and originality of the problem solution. The no-restriction condition as opposed to the restriction condition produced higher average quality and originality of the solutions. They found that unrestricted use of the related categories contributed to the solution quality, whereas unrestricted use of the unrelated categories contributed to the solution originality.

Why did category relatedness lead to higher originality in one condition and higher quality in another condition? In accord with relation element theory, Chaffin and Herrmann (1987) demonstrated that the relation between the information (categories) is not stored in our long-term memory. We tend to construct a relation between the given information on the spot by comparing common properties of the categories. Either we do the comparison by using multiple properties of the categories or we simply compare a subset of the categories that best accounts for the category exemplars. Based on this theory a later study done by Baughman and Mumford (1995) justified Mobley et al.'s (1992) findings. Unrelated categories will share only a few common properties thus making it difficult to generate a coherent and higher quality product, but it could lead to highly original products. This fits well with a common finding in brainstorming 
research of a high negative correlation of feasibility and originality of ideas generated. Baugman and Mumford (1995) extended Mobley et al.'s (1992) study with slight variations in the instructions and found that solution quality was affected by category interrelatedness. However, unlike Mobley's finding, this study found that diverse categories led to higher solution quality as opposed to originality. The difference in findings was attributed to the difference in task manipulation used in the two studies.

From the above studies the prediction of effects of category interrelatedness on quality and originality of solution was fully supported, but the two studies revealed contradictory findings about the effects of diverse categories on quality and originality of the solutions. Moreover, the studies have not reported the quantity of solutions generated. These inconsistent results suggest the need for further investigation of the effects of category relatedness.

In the above studies, the task used was to generate new categories by combining and reorganizing a given set of exemplars. This is equivalent to the concept of linking or connecting two unrelated ideas or attributes (cognitive templates) in the brainstorming literature championed by Goldenberg, Mazursky, and Solomon (1999a, 199b) and a random stimulation process by DeBono (1969). However, in the brainstorming literature, studies have only investigated how joining ideas gives rise to more unique ideas or solutions. It is desirable to see how connecting broad categories of high or low relatedness may give rise to a better set of ideas or solutions. The studies on relatedness have used individual participants. It will be interesting to see how group creativity is affected by such related category presentation. In an interactive group paradigm, overlapping of knowledge bases of the members should lead to more fluency (high clustering or convergent tendency) whereas the non-overlapping categories should lead to more flexibility (divergent tendency) (Brown et. al, 1998). 
In the case of overlapping subsets, recall of one idea (irrespective of individual or joint assignment) should act as a cue to recall another related idea (cognitive stimulation), whereas in the case of non-overlapping subsets, recall of one idea should act as a distraction to the train of thought to another person (cognitive interference). When the individuals are concentrating on their task and can see an irrelevant idea on the screen, two things can happen. They will ignore it and will switch back to their own category and start searching again. This frequent distraction and switching back will delay the performance. Alternatively, they will forget their assigned part and will start adding to or building upon the other person's category. This might lead to higher clustering (convergent tendency). In either case, the rate of ideation should be slower.

\section{$\underline{1.5 \text { Interactive versus nominal paradigm }}$}

The process of either collaborative stimulation or interference can happen in interactive groups but not in nominal brainstorming groups. Therefore, the nominal group condition can serve as a good comparison group for the above conditions. The variable of interactive versus nominal group condition was the third variable in this study.

Larey and Paulus (1999) found that nominal groups have the tendency of divergent thinking whereas the interactive groups have the tendency of convergent thinking. Nominal groups tend to generate more ideas by switching categories compared to interactive groups. On the other hand, the interactive groups get fixated in the most preferred topics for a longer period. This leads to the lack of fluency and flexibility in interactive groups. The Larey and Paulus (1999) study used face-to-face groups but Ziegler et al. (2000) found that even in EBS paradigm participants who could read other's ideas generated ideas from fewer categories than those who could not. Ziegler and colleagues also found that EBS groups generated many irrelevant ideas compared to electronic nominal groups. In contrast, since the nominal groups do not have this 
convergent tendency, they should generate ideas from all the assigned categories. This should lead to higher between category fluency (flexibility) in the nominal paradigm.

In sum, the above review of literature reveals that brainstorming research has not fully explored the influence of task decomposition in terms of assigned expertise (categories) to the group members in a computer mediated communication paradigm. Two pilot studies were done to examine the effects on the ideation process based on the degree of overlap of the knowledge bases. 


\section{CHAPTER 2}

\section{STUDY I}

Study 1 was an exploratory study, the goal of which was to test whether the area of expertise has an effect on ideation process. It was predicted that the groups with diverse expertise should generate a higher quantity of ideas compared with the groups with similar areas of expertise.

Previous studies have suggested that heterogeneous groups contribute to the production

of higher administrative innovations (e.g., Bental \& Jackson, 1989). Diehl (1991) found that heterogeneous interactive groups surveyed more categories of ideas than the homogenous interactive groups. The interactive groups with high diversity should bring unique ideas to the group as the members will have different perspectives to share. For example, a person from biology may generate ideas related to the biology field, a person from nursing from the nursing field and a person from architecture from that field. Additionally as the group members share their unique ideas, they will cognitively link and stimulate each others' ideas, which will lead to more unique ideas.

\section{$\underline{\text { 2.1. Participants and procedure }}$}

66 students at UT Arlington participated in the experiment. The study was a 2 (nominal/interactive) $\mathrm{X} 2$ (high/low diversity) between groups design. The task used for the study was to brainstorm on the "tourist problem". Basically the members were asked to generate 
ideas on how to improve the Dallas-Fort Worth area so that they can attract more tourists into the region.

The area of expertise in terms of academic major was operationalized. A high diversity group was a group in which the members belonged to different majors (e.g., psychology, nursing and math). For example, a low diversity group was a group in which the members belonged to the same major (e.g., all psychology majors). For the participants who did not have a major, they were assigned areas that they indicted as their hobbies. The group members were first sensitized about their area of expertise. Sensitization had two phases: diversity awareness and diversity application.

In the awareness phase the members were provided with a sheet of paper on which different majors were listed (Appendix J). The members chose their major from the list. Based on the member's choice of major each group was labeled as a high or low diversity group. After assigning the expertise to each member on the basis of their major, every member was made aware about each other's areas of expertise. Hollingshead (2000) found that when the members in a group believe that each member has a different area of expertise, they are more motivated to learn and remember their own area of expertise.

In the diversity application phase the participants were given a practice brainstorming problem -"How to improve UTA". The experimenter gave two ideas as examples for each member related to their respective areas of expertise. It was believed that such examples would help them to see the applicability of their expertise in a brainstorming task. Then the participants generated ideas for 10 minutes on the practice problem. Finally, the participants generated ideas on the tourist problem for 15 minutes. 


\section{$\underline{2.2 \text { Results and discussion }}$}

As previously demonstrated in the literature, the nominal groups generated a significantly higher quantity of ideas $(M=45.7, S D=5.1)$ compared to the interactive groups $(\mathrm{M}=84, S D=5.9), F(1,12)=6.68, p<.05$. However, the results did not reveal a significant effect of diversity (diversity of expertise) condition, $F(1,12)=1.23, p>.05$. However the means revealed that high diversity groups generated a higher quantity of ideas $(M=67.2, S D=5.4)$ compared to low-diversity groups $(M=62.5, S D=6.1)$. There are several limitations of this study. The first problem was that for many participants the major was undecided. Therefore, they were not sure what their area of expertise was. Second, the participants brainstormed in a face-to-face ideation paradigm. In such paradigm, the group members undergo production losses due to various group processes, which could limit the effect of their diversity in the "area of expertise". Moreover, the other observable diversities (e.g., gender, ethnicity, age) of the group members could have influenced the results. Therefore, I attributed the lack of a significant effect of diversity condition to a weak operationalization of the "area of expertise" in the group. With the above issues in mind, study 2 varied diversity in terms of category assignment. 


\section{CHAPTER 3}

\section{STUDY II}

Study II manipulated the "area of expertise" in terms of assignment of topics (categories) to the members by the experimenter. Consistent with Hollingshead's (2001) study, this study manipulated expertise by assigning them to the members. The members were assigned with categories related to the problem of "How to improve UT Arlington." A new variable that was tested in this study was the relatedness of the categories assigned. The details of category selection and assignment are explained in the method section of the main study. Each group consisted of three participants. The groups were individually or jointly assigned with categories. The individual assignment refers to assigning each member in the group with one category whereas the joint assignment refers to assigning all the three categories to all the three members of the group. The groups were further divided based on degree of relatedness of the assigned categories. The groups were either assigned categories of high or low relatedness.

The prediction was that the individual assignment would lead to the generation of a higher quantity of ideas compared to joint assignment. It was expected that the assignment of a unique part to each member would enhance the motivation and accountability in the group (Harkins \& Petty, 1982). The second prediction was that the assignment of unrelated areas would yield more ideas. Brown \& Paulus (2002) argued that low degree of overlap among the categories should activate the more inaccessible areas, thereby leading to higher number of ideas. Moreover, it was also predicted that the high number of ideas generated for the categories of low 
relatedness should be enhanced by the individual assignment paradigm. The motivation due to individual assignment should lead the group members to work harder and the assignment of unrelated areas should reduce the possibility of collaborative inhibition.

\section{$\underline{3.1 \text { Participants and procedure }}$}

81 participants from the Introduction to Psychology classes at the University of Texas at Arlington participated in the experiment. The design was a 2 (category relatedness) x 2(category assignment) between groups design. The task used for this study was the "UTA problem".

The paradigm used in this study was electronic brainstorming (EBS). It was presumed that the diversity in area of expertise could be more successfully tested in the EBS paradigm since the effects of other observable diversities will be minimized in such context. In this study the members were specifically instructed to pay attention to the ideas generated by others, as they would be tested on this at the end of the session.

\section{$\underline{3.2 \text { Results and discussion }}$}

There were no main effects of the relatedness and type of assignment conditions. However, the findings revealed a significant interaction between relatedness and assignment of category, $F(1,21)=5.39, p<.05$. In other words, in case of three categories joint assignment, groups generated the highest quantity of ideas when assigned with categories of low relatedness $(M=53.50, S D=11.77)$. In contrast, in case of the individual category assignment, assignment of highly related categories led to the highest quantity of ideas $(M=52.50, S D=5.6)$. Brown \& Paulus (2003) argued that presenting primes from low accessible categories could increase the total number of ideas by activating knowledge that would have gone untapped. In the joint assignment condition, the members were free to switch between the categories. Maybe this switching helped the members more in the unrelated category condition to tap the unexplored 
areas. In the case of the individual assignment condition, it is possible that the ideas generated by one member disrupted the ideation process of the other member in the group since their assigned areas had low degree of relatedness. 


\section{CHAPTER 4}

\section{MAIN STUDY}

In the pilot studies, evidence has emerged that assignment of categories could predict differences in group success on the ideation task. From the second pilot study it is clear that the joint assignment of highly related categories led to the least number of ideas generated. However, the second pilot study used only interactive groups. The outcomes could have been more clearly understood if there was a nominal group condition for comparison. Secondly, the study investigated the effects only in terms of quantity of ideas generated. It is important to further examine the quality as well as convergent tendencies in groups. Since quantity and average quality are not directly associated with each other, it will be interesting to investigate the findings for these measures for various conditions.

This study provided a comprehensive test of the effects of both assignment and relatedness of the assigned categories on the interactive and nominal ideation process (see appendix L for the design of the study). This study also included an interactive control group as a reference group. Studies have found that nominal groups perform at the level of electronic brainstorming groups as long as the groups are small (Dennis \& Williams 2003; Gallupe, et. al, 1991). When the members have different perspectives, and the perspectives are high or low in degree of relatedness, it will be important to know how an interactive group performs relative to a nominal group. 
Many studies have examined the convergent and divergent tendencies in groups (e.g., Nijstad \& Stroebe, 2006; Paulus \& Larey, 1999). However, very few studies have investigated the association of such tendencies with the quality of ideas generated. In the literature, studies have mostly considered divergence to be beneficial (e.g., Brown et al., 1998) for ideation. However, a convergent orientation also could lead to the enhancement of ideation process in terms of quality of ideas generated (Nijstad \& Stroebe, 2006). Therefore, it is important to investigate the effects of category assignment and relatedness on the convergent and divergent tendencies in groups.

\section{$\underline{4.1 \text { Hypotheses }}$}

Studies have found that interactive groups have a high convergent orientation (Larey \& Paulus, 1999; Nijstad \& Stroebe, 2006; Rietzschel et al., 2007). Interactive groups tend to get fixated to their preferred topics, which leads to more repetition of ideas from the preferred topics (convergent orientation) and less survey of additional categories. Similarly, Bouchard et al. (1974) speculated that if interactive groups become fixated in a category for too long, they tend to generate more ideas within the category and fewer ideas across different categories. This led to the following prediction:

Hypothesis I: Interactive groups should survey fewer categories of ideas and exhibit high clustering compared to nominal groups.

Group members assigned with three categories (joint assignment) should generate a higher quantity of ideas compared to the group members exposed to one category (individual assignment). When all of the members are assigned three categories, they can switch from one 
category to the other. This reduces the boredom due to generating ideas from the same area. Moreover generating ideas from the three categories simultaneously should reduce the response latency of group members. In the individual assignment condition, once a category is depleted the ideation will become slower. Moreover, exposure to ideas from others' categories may interfere with one's train of thought. Conversely, individual assignment may also lead to higher productivity. In accord with the theory of motivation, when the members are assigned a unique category they will be motivated to work hard (Harkins \& Petty, 1982). Moreover, due to individual assignment, each of the assigned categories will get a fair amount of individual attention. Therefore, ideas will be generated simultaneously from all of the assigned categories, which should lead to generation of a higher quantity of ideas. Hollingshead (1998) found that when each member is assigned with a different area of expertise, the members felt more responsible to recall ideas from their own assigned areas. These shared ideas will cognitively stimulate further ideas in an interactive group. Therefore there are two alternative predictions:

Hypothesis II a: The joint assignment condition should lead to a higher quantity of ideas and a greater flexibility compared to the individual assignment condition.

Hypothesis II b: The individual assignment condition should lead to a higher quantity of ideas but a less flexibility compared to joint assignment condition.

Having three assigned categories will lead to faster production of ideas compared to having only one assigned category. Moreover, having three categories will save time as the members can switch from one to other. This should be more beneficial in the interactive paradigm as one member's idea may cognitively stimulate another member's idea. Alternatively, interactive groups may get fixated on their preferred categories, leading to a greater convergent tendency (clustering). Therefore, there are two alternative predictions: 
Hypothesis IIIa: The joint assignment should lead to the highest quantity of ideas and more flexibility in the interactive group paradigm.

Hypothesis IIIb: The joint assignment should lead to high clustering and least flexibility in the interactive group paradigm.

Sherwood (1998) found that presenting the individual brainstormers with ideas from lowaccessible categories increases the overall number of ideas generated. Proctor (1993) contended that even in the case of computer users, "randomly generated words and semi-meaningful statements can set into motion a whole set of associations". According to the associative memory model (Brown \& Paulus, 2003) presenting primes from low accessible categories can increase the total number of ideas by activating knowledge that would have gone untapped. Therefore, the ideas generated from the categories that are low in relatedness should act as primes in activating categories that are relatively inaccessible. This should lead to a higher quantity of ideas generated and a higher quantity of categories explored.

Hypothesis IV: The groups assigned with categories of low relatedness should lead to the generation of more ideas and a higher flexibility compared with the groups assigned with categories of high relatedness.

Relatedness of categories should be beneficial in the interactive group condition more than in the nominal group condition. This is because cognitive stimulation or interference due to exposure to others ideas is absent in the nominal brainstorming paradigm.

Hypothesis V: The low relatedness of category condition should lead to highest number of ideas and most flexibility in the interactive group paradigm. 
If cognitive stimulation is the critical factor, then the interactive groups have the benefit of cognitive stimulation, which the nominal groups do not have. Categories with low relatedness should prime more inaccessible ideas leading to higher quantity of ideas generated compared to the categories of high relatedness. Furthermore, performance will be magnified by accountability and motivation associated with individual assignment of unique category. Basden et al. (1997) found that when the group members were instructed to recall from a common set of categories, there was a collaborative inhibition effect. More specifically, they found that collaborative inhibition occurred when all group members recalled items from all the assigned categories. Collaborative inhibition posits that if a word is recalled by one person, the thought processes of the other person who already is about to recall the word will be disrupted. In their study when the members were asked to recall from separate categories, there was a less effect of collaborative inhibition.

If social validation or similarity is the critical factor, then the interactive groups will generate the highest number of ideas in the joint assignment of highly related categories condition. Wittenbaum, Hubbell and Zuckerman (1999) reported evidence regarding a mutual enhancement effect of discussing shared information. Participants in their study evaluated one another more positively when shared information was mentioned. This mutual enhancement might motivate the participants to generate more ideas in groups. Similarity attraction theory also posits that when the members see ideas similar to their own line of thought, they will feel motivated to work together (Byrne, 1961, 1971). Furthermore, joint category assignment will enhance performance. Since the members will be assigned with all three categories to generate ideas, they can switch easily to another category whenever they run short of ideas in one category. 
Hypothesis VIa : The number of ideas generated by the interactive groups in the low related category condition will be enhanced by the individual assignment of categories.

Hypothesis VIb: The number of ideas generated by the interactive groups in the high related category condition will be enhanced by the joint assignment of categories.

Regarding perceived enjoyment, it is not clear whether the members will enjoy working with a group assigned with similar topics or dissimilar topics. According to similarity attraction theory the members should enjoy working together (joint assignment) on the related topics. However, assigning highly related topics may lead to the generation of more similar (less original) ideas. Moreover, there is a possibility that the members will run short of ideas faster as they will be generating ideas from a common overlapping area. Regarding the assignment of high/low related topics, no evidence exists in the literature regarding its effects on perceived enjoyment in a brainstorming task. Therefore, the current investigation did not have a directional hypothesis for perceived enjoyment.

\subsection{Method}

\subsubsection{Participants}

Two-hundred and seventy undergraduate students were sampled from six different sections of the introductory psychology course at the University of Texas at Arlington. The participants partially fulfilled a research requirement for the class. Before the beginning of the experiment, the experimenter asked the members of each group whether they knew each other from prior interactions. Whenever the participants indicated they had a prior acquaintance, one or more were assigned to the nominal condition so that only strangers performed as a group. The age of the participants ranged from 18 to 38 years. There were 40 groups in each of the nominal and interactive group conditions. Each of the group conditions were sub-divided into four 
conditions-low related/ individual assignment, high related/ individual assignment, low related/joint assignment, and high related/joint assignment condition (Appendix L). Each of the four conditions consisted of 10 groups. Each group consisted of three participants. There was also a separate control group condition, which consisted of 10 groups with three participants in each group.

\subsubsection{Materials}

The participants were assigned to individual rooms and a desktop computer. For the nominal brainstorming condition, each member of the group typed the ideas in a Microsoft Word File on the desktop computer. The participants also filled in a pre-experimental and a postexperimental questionnaire. The participants were given the task of brainstorming on the problem of how to improve UT Arlington. For the interactive group condition the participants were provided with instruction sheets regarding the brainstorming rules, and instructions for using the EBS tool - the Yahoo Chat System. Although we are not aware of any studies that used Yahoo Chat for electronic brainstorming, this tool is very similar to "Topic Commentator" in “Group Decision Support Systems” (GDSS) (cf., Dugosh \& Paulus, 2005; Pissara \& Jesuino, 2005). In Yahoo Chat one can see the contributions of the group members in on the monitor as one is generating ideas. One can scroll up at any time to see any idea that was generated before.

\subsubsection{Design}

The design was a 2(interactive vs. nominal) x 2 (high vs. low relatedness) x 2(individual vs. joint assignment) between groups design with an added control condition of interactive groups without any manipulation.

\subsubsection{Procedure (Interactive groups)}

Upon arriving at the designated area, each group of participants was greeted by an 
experimenter who gave each of the group members a consent form to read and sign. Each participant was asked to sit separately in three corners of the room and given a background questionnaire for demographic information (see Appendix A). To assign the categories to the participants, the experimenter requested the participants to come to the round table at the center of the room to draw lots. Three categories were written on three different slips and each participant was asked to draw a slip and keep it to him or herself. The experimenter then gave the necessary instructions based on the type of assignment (see Appendices F \& G).

To ensure that the participants in the experimental condition paid attention to the ideas generated, they were told that they would be tested for their recall of the ideas after the session ended (cf., Dugosh, Paulus, Roland, \& Yang, 2000). The experimenter announced the three categories that were assigned, but no one knew who got what category. In the joint assignment condition each participant drew a slip, and each slip had the same three categories written on it. After drawing their slips, the participants went back to their seats. The experimenter gave instructions and demonstrated to the participants how to use the Yahoo Chat by using the desktop computer in the room. The participants were made aware that there were four login names - brainstormer 1 , brainstormer 2 , brainstormer 3 , and experimenter. Then each participant was randomly assigned to one of the first three login names. The fourth login name belonged to the experimenter. The participants were also told that the experimenter would be giving them instructions from time to time, and they were expected to act accordingly. On ensuring that everyone understood how to use the tool, the experimenter handed out a sheet of paper with brainstorming rules to each of the participants (see Appendix B). The experimenter read the rules along with the participants. Finally, the participants were requested to take their slips with them and to follow the experimenter to the individual rooms. Each individual was assigned with an 
individual desktop computer inside the room. The Yahoo chat tool was already opened on the monitor. The topic for brainstorming was on the desk next to the computer. The participants were asked to read the problem topic and not to start with the task until they saw the experimenter's instructions on the monitor. The experimenter went back to the main lab, sent a message to the participants to start with their brainstorming task and recorded the time since the message was sent. The participants, including the experimenter, could see each other's ideas with the names next to each idea as Brainstormer 1,2 or 3. Thus, each participant knew which brainstormer generated the idea but did not know who the person was. After 15 minutes, the experimenter sent a message to stop generating ideas and that she would be with them in a moment. The experimenter then gave an affect questionnaire (Appendix $\mathrm{K}$ ) to each of the participants to complete and instructed the participants to come back to the main lab when they finished answering the questionnaire. The participants were then debriefed and thanked.

\subsubsection{Procedure (Nominal groups)}

Upon arriving at the designated area, each group of participants was greeted by an experimenter who gave each of the group members a consent form to read and sign. Each participant was made to sit separately in three corners of the room and given a background questionnaire for demographic information (Appendix A). Next, to assign the categories to the participants, the experimenter requested the participants to come to the round table at the center of the room to draw lots. For the individual assignment condition, three categories were written on three different slips and each participant was asked to draw a slip and keep it to him or herself. In the joint assignment condition, each participant drew a slip and each slip had the same three categories written on it. The participants were then requested to take their slips with them and to follow the experimenter to their individual rooms. Each individual was 
assigned with an individual desktop computer inside the room. The Yahoo Chat was already opened on the monitor. The experimenter then gave the necessary instructions based on the type of assignment (Appendices H \& I). To ensure that the participants paid attention to their own ideas generated, they were told that they would be tested for their recall of the ideas after the session ended (cf., Dugosh et al., 2000). The experimenter then demonstrated to each participant how to use the Yahoo Chat Tool by using the desktop computer in the room. Each participant was made aware that he/she was randomly assigned with a login name. They were further informed that the experimenter would also be logged in to give them instructions from time to time, and they were expected to act accordingly. On ensuring that they understood how to use the tool, the experimenter handed out a sheet of paper with brainstorming rules to each of the participants (Appendix C). The experimenter read the rules along with the participants. The topic for brainstorming was on the desk next to the computer. The participants were asked to read the problem and not to start with the task until they saw the experimenter's instructions on the monitor. In this nominal condition, the experimenter gave instructions and a demonstration regarding Yahoo Chat individually to each participant in their room. The experimenter went back to the main lab, sent a message to the participants to start with their brainstorming task, and recorded the time since the message was sent. Each participant could see only the experimenter as logged in and generated ideas alone for 15 minutes. After 15 minutes, the experimenter sent a message to participants to stop generating ideas, and that she would be with them in a moment. The experimenter then gave an affect questionnaire (Appendix $\mathrm{O}$ ) to each of the participants to complete and instructed them to come back to the main lab when they finished answering the questionnaire. The participants were then debriefed and thanked. 


\subsubsection{Dependent variables and scoring}

The dependent variables used in this study were quantity, flexibility, clustering, quality and perceived enjoyment of the brainstorming task. Quantity was defined as the total number of non-repeated ideas generated. Flexibility was the number of categories surveyed at least once. Clustering (Adjusted Ratio Clustering) measured the extent to which the consecutive ideas fell in the same category, corrected for chance (see Roenker, Thompson \& Brown, 1973) for each participant. ARC was calculated by using the following formulae:

$$
\begin{aligned}
& A R C=\frac{R-E(R)}{\max R-E(R)} \\
& E(R)=\frac{\sum\left(\mathrm{n}_{\mathrm{i}}\right)^{2}}{N}-1
\end{aligned}
$$

$\mathrm{R}=$ Number of observed category repetitions

$\mathrm{E}(\mathrm{R})=$ Expected number of category repetitions due to chance

MaxR = Maximum number of category repetitions $(\mathrm{N}-\mathrm{K})$

$\mathrm{N}=$ Total number of ideas generated

$\mathrm{K}=$ Number of categories surveyed

$\mathrm{n}_{\mathrm{i}}=$ Number of ideas in category $\mathrm{i}$

$\mathrm{ARC}$ is mathematically independent of the number of ideas generated and the number of categories surveyed. A lower value of ARC means less clustering (less convergence) and more switching (more divergence) of categories. Therefore, I will use the terms convergence and clustering interchangeably. To categorize the ideas, first each idea was rated by using the 
category codes as shown in Appendix P. Next, category repetition was measured. If the current idea (a) is from the same category as the last idea (a-1) then it was counted as a repetition. Each repetition was given a frequency of one. In the course of measuring the number of observed category repetitions, the raters often came across ideas that belonged to two different categories. For example, for an idea like "teachers should post class-notes on WEBCT", the raters felt that this idea could belong to two different categories- teachers as well as technology. In such a case, the idea was categorized as "teacher/technology" (TEA/TCH). If the idea generated prior to this idea belonged exclusively to either the category of teacher or technology, the repetition of the current ideas was considered partial. Therefore, it was given a frequency of .5. However if the prior idea was also an idea that belonged to TEA/TCH (for example, "teachers should use PowerPoint slides in their lectures") then the current idea was given the frequency of 1 for repetition.

Quality was defined as the average originality of ideas generated. The ideas were rated for originality by a trained rater on a 5-point Likert scale. The average originality was calculated by averaging the ratings for all of the ideas in a group. A difference of 1-point between the raters was considered as same rating whereas a difference of at least 2 point in rating was considered as difference in rating (Diehl \& Stroebe, 1987). The agreement between the raters was measured in terms of Cohen's Kappa. Perceived enjoyment was measured based on the participants' responses to the following item in the post experimental questionnaire - "How much did you enjoy the brainstorming session?"

\subsubsection{Forming Categories}

In a pilot study, the categories were formed by the following method. The experimenter examined previous studies (Baruah \& Paulus, 2007; Nakui, 2006; Putman \& Paulus, 2007) using 
the "UT Arlington problem" as a topic of brainstorming. An initially high number of categories used in the above studies were reduced to 19 broad categories for analysis. See Appendix P for the categories used for rating the ideas and definition of each of the categories.

For forming the combinations of related and unrelated categories, the 11 most frequently used categories were found from the above three studies. They were classes, campus-activities, food, buildings, teachers, technology, parking, campus-safety, addition/construction/renovation, student-welfare, and campus beautification. Using the 11 categories, one hundred and sixty-five combinations of three categories out of the above eleven categories were possible. The experimenter rated each combination on a 5-point Likert scale based on how related the categories were. To check the reliability, two other persons familiar with the rating of the ideas related to the "UTA problem" were given a randomly selected subset of 15 sets of categories to rate (Barsalou, 1991; Mobley et al.,1992) (see Appendix N). The interrater agreement measured by Cronbach's alpha was found to be .93 . The relatedness rating yielded nine sets of the categories that were high (5 point) or low in relatedness (1 point) (Appendix N). Unfortunately, in spite of being high in frequency, the categories of food and parking were not rated as one of the most or least related categories. Based on 9 categories four different combinations were found to be most or least related (Appendix M). These four combinations were presented to the groups at least with one repetition under each manipulated condition. More specifically, each of the eight manipulated conditions (see Appendix L for design of the study) had 10 groups. Therefore the above four combinations of categories occurred at least once in each manipulated condition. 


\section{CHAPTER 5}

\section{RESULTS}

\section{$\underline{5.1 \text { Manipulation checks and preliminary analyses }}$}

As a check on the manipulation of category assignment, the participants were asked the following question -"Were you instructed that you were responsible for brainstorming on one or on three topics?" All participants in the individual assignment condition reported correctly that they were assigned with one topic and those in the joint assignment condition reported that they were assigned three topics. Thus, the manipulation of category assignment was successful.

As a check on the manipulation of relatedness, the participants were asked, "How different were the types of ideas you generated about your topic or topics from those generated by others about their topic or topics"? A one-way ANOVA was performed with related and unrelated category groups. The ANOVA revealed a significant effect, $F(1,29)=4.12, p<.05$. Groups assigned with unrelated categories demonstrated a higher average rating $(M=4.97)$ than those assigned with related categories $(M=3.94)$. Thus, the manipulation for relatedness was successful.

Ideas produced by each participant were counted and duplicates were removed for both interactive and nominal groups. An independent second rater scored the duplicates for a random set of 100 participants resulting in an inter-rater agreement of 98.22\%. Next, all ideas were categorized into 19 preexisting categories developed by Nakui (2006). An independent second rater categorized $25 \%$ of the data set and the inter-rater agreement (Cohen's Kappa) was .91. 


\subsection{Correlations}

A multiple correlation for dependent variables of quantity, clustering, flexibility (categories surveyed), originality and perceived enjoyment was performed for all the conditions combined (see Table 1). Quantity was positively correlated with the flexibility $(r=.53, p<.01)$. Quantity was also positively correlated with quality (average originality) of ideas generated $(r=.28, p<.05)$. Clustering was found to be negatively correlated with the quality of ideas generated $(r=-.30, p<.005)$.

Next, separate multiple correlations were performed for each of interactive and nominal groups (see tables $2 \& 3$ ). For interactive groups, there was a significant positive correlation between quantity and flexibility $(r=.58, p<.01)$ and quantity and originality $(r=.35, p<.05)$ respectively. There was also a significant positive correlation between flexibility of ideas

Table 1: Overall correlations for the dependent variables

\begin{tabular}{lcccc}
\hline & Quantity & Flexibility & Clustering & Originality \\
\hline Flexibility & $0.53^{* *}$ & & \\
Clustering & -0.09 & -0.22 & & \\
Originality & $0.28^{*}$ & -0.06 & $-0.30^{* *}$ & \\
Enjoyment & 0.07 & 0.05 & 0.2 & -0.17 \\
\hline
\end{tabular}

Note: $* p<.05, * * p<.005$ 
generated and perceived enjoyment in the brainstorming task $(r=.36, p<.05)$ for interactive groups. For nominal groups, there was a significant positive correlation of quantity and flexibility $(r=.47, p<.01)$. However, the correlation between originality and quantity was no more significant. The same was the case with the correlation between flexibility and perceived enjoyment.

Next, separate multiple correlations were performed for each of joint and individual assignment conditions (see tables $4 \& 5$ ). For the joint assignment condition, there was a high positive correlation between flexibility and quantity of ideas generated $(r=.60, p<.001)$. However, flexibility was negatively correlated with clustering if ideas $(r=-.33, p<.05)$. Clustering was found to be positively correlated with enjoyment $(r=.35, p<.05)$ but negatively correlated with the originality of ideas generated $(r=-.42, p<.01)$. For the individual assignment condition, quantity was positively correlated with flexibility $(r=.40, p<.01)$ and the originality of the ideas generated $(r=.40, p<.01)$.

Finally, separate multiple correlations were performed for each of high and low related category conditions (see tables $6 \& 7$ ). For the low related category assignment condition, quantity was positively correlated with flexibility $(r=.47, p<.005)$ and originality of ideas generated $(r=.36, p<.05)$. Perceived enjoyment was found to be positively correlated with clustering $(r=.36, p<.05)$. For the high related category assignment condition, quantity was again found to be positively correlated with flexibility $(r=.56, p<.001)$ but not with the originality of ideas generated. However the originality of ideas was found to be negatively correlated with clustering $(r=-.51, p<.005)$. The enjoyment was not correlated with clustering. 
Table 2: Correlations of dependent variables for interactive groups only

\begin{tabular}{|c|c|c|c|c|}
\hline & Quantity & Flexibility & Clustering & Originality \\
\hline Flexibility & $0.58 * *$ & & & \\
\hline Clustering & 0.02 & -0.13 & & \\
\hline Originality & $0.35^{*}$ & -0.04 & -0.22 & \\
\hline Enjoyment & 0.18 & $0.36^{*}$ & 0.08 & -0.28 \\
\hline
\end{tabular}

Table 3: Correlations of dependent variables for nominal groups only

\begin{tabular}{lllll}
\hline & Quantity & Flexibility & Clustering & Originality \\
\hline Flexibility & $0.47 * *$ & & \\
Clustering & 0.05 & -0.18 & & \\
Originality & 0.11 & -0.31 & 0.18 & 0.09 \\
Enjoyment & 0.07 & -0.17 & 0.31 & \\
\hline Note: $* * p<.01$ & &
\end{tabular}


Table 4: Correlations of dependent variables for joint assignment only

\begin{tabular}{lllll}
\hline & Quantity & Flexibility & Clustering & Originality \\
\hline Flexibility & $0.60^{* *}$ & & & \\
Clustering & -0.20 & $-0.33^{*}$ & & \\
Originality & 0.20 & -0.04 & -0.42 & -0.27 \\
Enjoyment & -0.10 & -0.12 & $0.35^{*}$ & \\
\hline Note: & & & &
\end{tabular}

Note: $* p<.05, * * p<.005$

Table 5: Correlations of dependent variables for individual assignment only

\begin{tabular}{lllll}
\hline & Quantity & Flexibility & Clustering & Originality \\
\hline Flexibility & $0.41^{* *}$ & & & \\
Clustering & -0.06 & -0.26 & -0.17 & \\
Originality & $0.40^{*}$ & -0.05 & 0.12 & -0.09 \\
Enjoyment & 0.12 & 0.07 & &
\end{tabular}

Note: $* p<.05, * * p<.005$ 
Table 6: Correlations of dependent variables for high-related categories only

\begin{tabular}{lllll}
\hline & Quantity & Flexibility & Clustering & Originality \\
\hline Flexibility & $0.56^{* *}$ & & \\
Clustering & -0.15 & -0.19 & & \\
Originality & 0.25 & -0.14 & $-0.51^{* *}$ & -0.25 \\
Enjoyment & 0.17 & 0.06 & 0.08 & \\
\hline Note: $* p<.05, * * p<.005$ & & &
\end{tabular}

Table 7: Correlations of dependent variables for low-related categories only

\begin{tabular}{lllll}
\hline & Quantity & Flexibility & Clustering & Originality \\
\hline Flexibility & $0.47 * *$ & & \\
Clustering & 0.04 & -0.16 & & \\
Originality & 0.36 & 0.14 & -0.06 & -0.25 \\
Enjoyment & -0.03 & -0.06 & $0.36 *$ & \\
\hline Note: $* p<.05, * * p<.005$ & & &
\end{tabular}




\subsection{Group performance data}

A 2 (groups) x 2 (relatedness) x 2 (assignment) MANOVA was performed for quantity, clustering, flexibility, quality and perceived enjoyment. The predictor variables were categoryrelatedness (high vs. low relatedness), category-assignment (individual vs. joint assignment), and group-type (nominal vs. interactive).

With the use of Wilks' criterion, the combined dependent variables were significantly affected by type of groups, $F(5,63)=7.07, \mathrm{p}<.005$, type of assignment $F(5,63)=3.84, p<$ .05 , and type of category-relatedness, $F(5,63)=2.49, p<.05$. There was also a significant interaction effect of type of group and type of assignment, $F(5,63)=4.47, p<.05$. The results revealed an association between the combined dependent measures (total number of ideas, flexibility, clustering, quality and enjoyment) with each of group-type $\left(\eta^{2}=.37\right)$, assignment-type $\left(\eta^{2}=.18\right)$ and category-relatedness $\left(\eta^{2}=.16\right)($ see table 8$)$.

Table 8: Multivariate Tests

\begin{tabular}{lccccc}
\hline Effect & \multicolumn{1}{c}{ Wilks' Lambda } & F & Hypothesis df & Error df & Partial $\eta^{2}$ \\
\hline Groups & .64 & $7.07^{* *}$ & 5 & 63 & .36 \\
Assignment & .74 & $4.47^{* *}$ & 5 & 63 & .26 \\
Relatedness & .84 & $2.49^{*}$ & 5 & 63 & .17 \\
Groups*Assignment & .86 & $2.31^{\mathrm{a}}$ & 5 & 63 & .16 \\
Groups* Relatedness & .94 & .77 & 5 & 63 & .06 \\
Assignment*Relatedness & .88 & 1.76 & 5 & 63 & .12 \\
Groups*Assignment* & .87 & 1.86 & & & .13 \\
Relatedness & & 5 & 63 & \\
\hline
\end{tabular}

Note: $* p<.05, * * p<.005,{ }^{a} p=.05$. 
Next, a univariate analysis was performed for each of the dependent variables - quantity, flexibility, clustering, originality and perceived enjoyment. Table 9 shows the results for the measures as a function of group-type, assignment-type and category-type respectively. Figures 4 through 8 graphically represent the means for all the five dependent variables as a function of group-type, assignment-type and category-type.

\subsubsection{Quantity}

A 2(groups) x 2(relatedness) x 2(assignment) between subjects ANOVA was performed for total number of ideas generated. Table 10 shows the number of ideas generated for the type of groups, category relatedness and category assignment. There was a significant main effect of the type of category assignment, $F(1,72)=4.67, p<.05$. Joint assignment (all members were jointly assigned with 3 categories) groups generated more ideas $(M=62.40, S D=17.16)$ than the individual assignment groups (each member of the group assigned with a category) $(M=54.35$, $S D=16.57)$ groups. The finding is consistent with Hypothesis IIa. There was a marginally significant effect of group condition, $F(1,72)=3.28, p=.07$. The nominal groups generated slightly more ideas $(M=61.75, S D=18.72)$ compared to the interactive groups $(M=55.00, S D$ $=15.11)$. There was a no significant main effect for relatedness on the number of ideas generated (see figure 4).

To further investigate the effects of category assignment, a 2(relatedness) $\mathrm{x}$ 2(assignment) between group ANOVA was performed for each of the interactive and nominal groups separately. There was a significant main effect of category assignment in the interactive group condition, $F(1,36)=4.37, p<.05$, with the joint assignment condition $(M=60.65$, $S D=15.98$ ) resulting in a higher number of ideas compared to the individual assignment condition $(M=49.35, S D=12.09)$ condition (see figure 1$)$. The finding is consistent with 
Table 9: Univariate tests for nominal and interactive combined

\begin{tabular}{|c|c|c|c|c|}
\hline$\underline{\text { IV }}$ & $\mathrm{DV}$ & Univariate $\mathrm{F}$ & $\mathrm{df}$ & Partial $\eta^{2}$ \\
\hline \multirow[t]{5}{*}{ Groups } & Quantity & 3.28 & $1 / 72$ & .04 \\
\hline & Flexibility & $4.24 *$ & $1 / 72$ & .60 \\
\hline & Clustering & $33.73 * *$ & $1 / 72$ & .32 \\
\hline & Originality & $12.65 * *$ & $1 / 72$ & .15 \\
\hline & Enjoyment & $4.13^{*}$ & $1 / 67$ & .06 \\
\hline \multirow[t]{5}{*}{ Relatedness } & Quantity & 2.95 & $1 / 72$ & .04 \\
\hline & Flexibility & $10.86 * *$ & $1 / 72$ & .13 \\
\hline & Clustering & 2.67 & $1 / 72$ & .03 \\
\hline & Originality & 1.05 & $1 / 72$ & .01 \\
\hline & Enjoyment & 2.13 & $1 / 67$ & .03 \\
\hline \multirow[t]{5}{*}{ Assignment } & Quantity & $4.67 *$ & $1 / 72$ & .06 \\
\hline & Flexibility & $8.80 * *$ & $1 / 72$ & .10 \\
\hline & Clustering & $4.08^{*}$ & $1 / 72$ & .05 \\
\hline & Originality & .42 & $1 / 72$ & .01 \\
\hline & Enjoyment & 1.50 & $1 / 67$ & .02 \\
\hline \multirow[t]{4}{*}{ Groups* Assign } & Quantity & .76 & $1 / 72$ & .01 \\
\hline & Flexibility & .82 & $1 / 72$ & .01 \\
\hline & Clustering & $6.42 *$ & $1 / 72$ & .08 \\
\hline & Originality & 1.03 & $1 / 72$ & .01 \\
\hline
\end{tabular}


Table 9 - continued

\begin{tabular}{|c|c|c|c|c|}
\hline$\underline{\mathrm{IV}}$ & $\mathrm{DV}$ & Univariate $\mathrm{F}$ & $\mathrm{df}$ & Partial $\eta^{2}$ \\
\hline & Enjoyment & $3.12^{\mathrm{b}}$ & $1 / 67$ & .05 \\
\hline \multirow[t]{5}{*}{ Relatedness * Assign } & Quantity & .23 & $1 / 72$ & .00 \\
\hline & Flexibility & 2.26 & $1 / 72$ & .03 \\
\hline & Clustering & .24 & $1 / 72$ & .00 \\
\hline & Originality & .10 & $1 / 72$ & .00 \\
\hline & Enjoyment & $3.88^{\mathrm{a}}$ & $1 / 67$ & .06 \\
\hline \multirow[t]{5}{*}{ Groups * Assign * Related } & Quantity & .01 & $1 / 72$ & .00 \\
\hline & Flexibility & 1.53 & $1 / 72$ & .02 \\
\hline & Clustering & .02 & $1 / 72$ & .00 \\
\hline & Originality & $6.59 *$ & $1 / 72$ & .09 \\
\hline & Enjoyment & .22 & $1 / 67$ & .00 \\
\hline
\end{tabular}


Hypothesis IIIa. However, there was no significant effect of the relatedness condition. There was also no interaction between relatedness and assignment condition. In the case of the nominal groups, ANOVA did not reveal a significant main effect of type of assignment and category relatedness, or an interaction between the two.

\subsubsection{Quantity - with respect to the control groups}

A one-way ANOVA was performed only for the interactive-experimental groups and the interactive-control groups as a function of type of assignment. The effect of assignment condition was found to be significant $F(2,47)=3.38, p<.05$. In a subsequent posthoc test, the control group was compared to experimental groups using Dunnett's t-tests. Dunnett's test revealed a marginally significant difference between the control group (no assignment) and the joint assignment group, $(M=12.45, p=.07)$ and no significant difference between the no assignment and the individual assignment group in terms of total number of ideas generated (see figure 2). The means reveal that the joint assignment condition yielded the highest number of ideas compared with the individual assignment and the no assignment conditions. However there was a significant difference between the individual assignment and the joint assignment condition $(M=2.20, p=.04)$. Another one-way ANOVA was performed only for the interactive-experimental groups and the interactive-control groups as a function of category relatedness. There was a no significant effect of category relatedness for interactive experimental groups with respect to the control group. 
Table 10: Quantity of ideas generated as a function of type of assignment and category relatedness

Group Type

$\underline{\text { High Related }}$

$\underline{\text { Low Related }}$

Ind. Assign Joint Assign

Ind. Assign Joint Assign

Interactive

M

48.30

56.60

50.40

64.70

$S D$

11.60

18.80

13.10

12.20

Nominal

$\begin{array}{lrrrr}M & 57.30 & 58.50 & 61.40 & 69.80 \\ S D & 15.75 & 17.51 & 22.63 & 18.60\end{array}$

Total

$\begin{array}{rrrrr}M & 52.80 & 57.55 & 55.9 & 67.25 \\ (S D) & 13.68 & 18.16 & 17.87 & 15.40\end{array}$




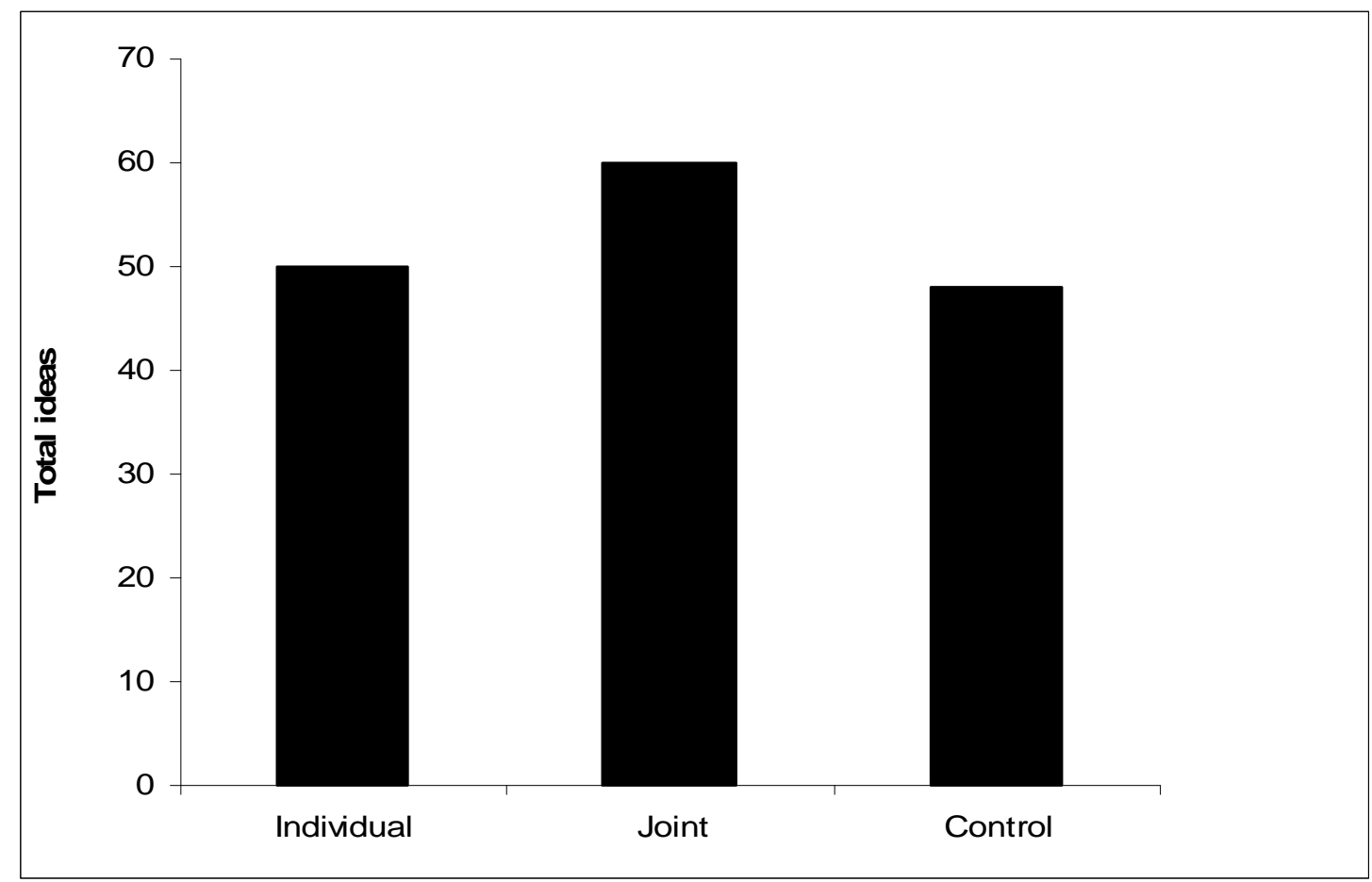

Figure 1. Quantity of ideas for interactive experimental and interactive control group as a function of type of assignment

\subsubsection{Flexibility}

A 2(groups) x 2(relatedness) x 2(assignment) between subjects ANOVA was performed for the total number of categories surveyed (flexibility). Table 11 shows the average number of categories explored for the type of groups, relatedness and assignments respectively. There was a significant main effect of group condition, $F(1,72)=4.24, p<.05$, with nominal groups $(M=$ 12.63, $S D=2.47)$ surveying more categories than interactive groups $(M=11.38, S D=3.22)$. Thus hypothesis I was supported. There was also a significant main effect of category relatedness, $F(1,72)=10.86, p<.005$. Groups assigned with low related categories exhibited more flexibility $(M=13.00, S D=2.32)$ compared to the groups assigned with categories of high relatedness $(M=11.00, S D=3.28)$. This finding is partially consistent with hypothesis IV that 
low relatedness of categories should yield a higher number of ideas and a higher number of categories surveyed. The type of assignment was also found to be significant, $F(1,72)=8.80, p$ $<.005$, with the joint assignment group exploring more categories $(M=12.9, S D=2.70)$ than the individual assignment groups $(M=11.10, S D=3.17)$. Consistent with Hypothesis IIa, joint assignment led to high flexibility compared to the individual assignment condition.

To further investigate the effects of flexibility, a 2 (relatedness) x 2(assignment) between group ANOVA was performed for each of the interactive and nominal groups separately. For interactive groups, category assignment was found to be significant, $F(1,36)=7.68, p<.01$. Joint assignment $(M=12.55, S D=2.82)$ led to survey of more categories than the individual assignment condition $(M=10.20, S D=3.24)$. In contrast to this finding, it was predicted that joint assignment should lead to the survey of fewer categories (less flexibility) compared to individual assignment condition in interactive groups. However, category assignment was not found to be significant in the nominal group condition. (figure 5). Therefore, the main effect of the type of assignment found in three-way ANOVA can primarily be attributed to the interactive groups only. There was also a significant main effect of category relatedness, $F(1,36)=10.52, p$ $<.005$. Groups assigned with highly related categories $(M=10.00, S D=3.55)$ surveyed fewer categories (less flexibility) compared to the groups assigned with categories of low relatedness, $(M=12.75, S D=2.17)$. The above finding supported prediction $\mathrm{V}$ that categories of low relatedness should lead to more flexibility in the interactive groups. No interaction effect was found between relatedness and assignment condition. Separate analysis for nominal groups revealed no significant effects of either relatedness or category assignment in flexibility. 
Table 11: Average flexibility as a function of type of assignment and category relatedness

Group Type

$\underline{\text { High Related }}$

$\underline{\text { Low Related }}$

Ind. Assign Joint Assign

Ind. Assign Joint Assign

Interactive

$\begin{array}{lllll}M & 8.20 & 11.80 & 12.20 & 13.3 \\ S D & 2.97 & 3.26 & 2.10 & 2.21\end{array}$

Nominal

$M$

11.50

12.50

12.50

14.00

$S D$

2.88

3.20

2.99

1.63

Total

$M$

9.85

12.15

12.35

13.65

$(S D)$

2.92

3.23

2.54

0.82

\subsubsection{Flexibility - with respect to the control group}

A one-way ANOVA was performed only for the interactive-experimental groups and the interactive-control groups in terms of flexibility. Category-relatedness was found to be significant, $F(2,47)=4.29, p<.05$. Dunnett's test revealed that unrelated category groups surveyed significantly more categories $(M=12.55)$ compared to related category groups $(M=$ 9.95). However, there was no significant difference between the control groups and the groups assigned with unrelated categories. This indicates that the performance of interactive groups is lowered in terms of flexibility of ideas generated when they are assigned with related categories (see figure 2). Another one-way ANOVA was performed for the interactive-experimental 
groups and the interactive-control groups for type of category assignment. However, category assignment was not found to be significant with respect to the control group.

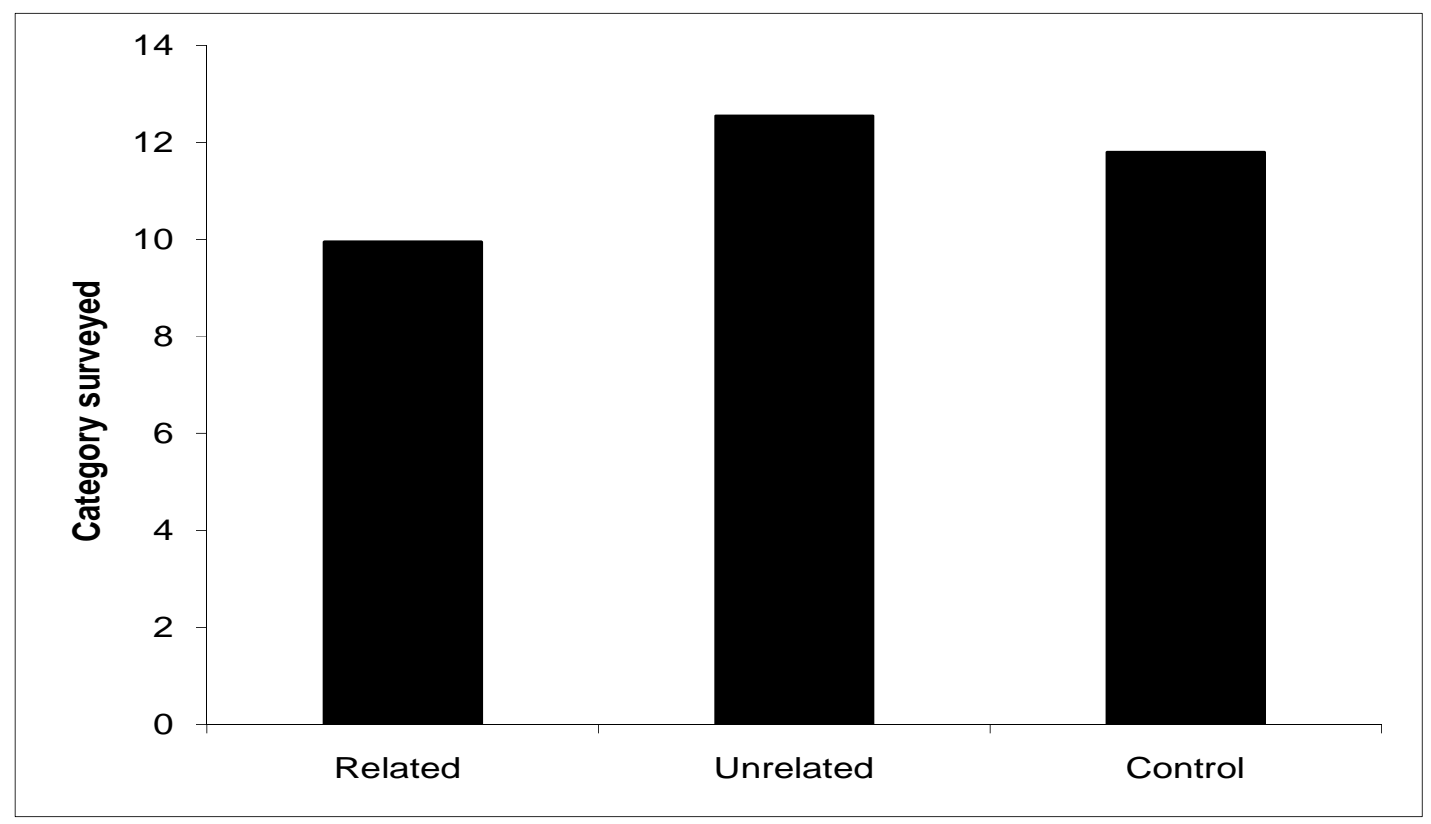

Figure 2. Average flexibility for interactive experimental and interactive control groups as a function of category relatedness

\subsubsection{Clustering}

A 2(groups) x 2(relatedness) x 2(assignment) between groups ANOVA was performed for clustering. Table 12 shows the clustering of ideas for the type of groups, category relatedness and category assignments. There was a significant main effect of group condition, $\quad F(1,72)=$ 33.73, $p<.0001$. The interactive groups $(M=.25, S D=.16)$ showed significantly more clustering compared to the nominal groups $(M=.09, S D=.06)$. This finding supports the prediction regarding high convergence in interactive groups. There was also a significant main effect of category assignment, $F(1,72)=4.08, p<.05$. Groups with joint assignment $(M=.20$, $S D=0.10)$ exhibited more clustering than groups with individual assignment $(M=.14, S D=$ .12). A significant interaction effect was found between the group and the assignment condition, 
$F(1,72)=6.43, p<.05$. Interactive groups with joint assignment of categories led to most clustering $(M=.30, S D=.15)$ (see figure 3). Consistent with Hypothesis IIIb, the interactive group jointly assigned with three categories showed maximum repetition of ideas from the same category. There was no significant main effect of relatedness nor was there an interaction of relatedness with group or assignment condition.

To further investigate the effects of clustering in each of the nominal and interactive groups separately, a 2(relatedness) x 2(assignment) between group ANOVA was performed. In interactive groups, category assignment was again found to be significant, $F(1,36)=5.82, p<$ .05. Group assigned with an individual category showed less clustering $(M=.19, S D=.16)$ compared to the groups in the joint assignment condition $(M=.30, S D=.15)$. Category relatedness was not found to be significant in the interactive groups. For the nominal groups none of the conditions was found to be significantly different in terms of clustering (see figure 6).

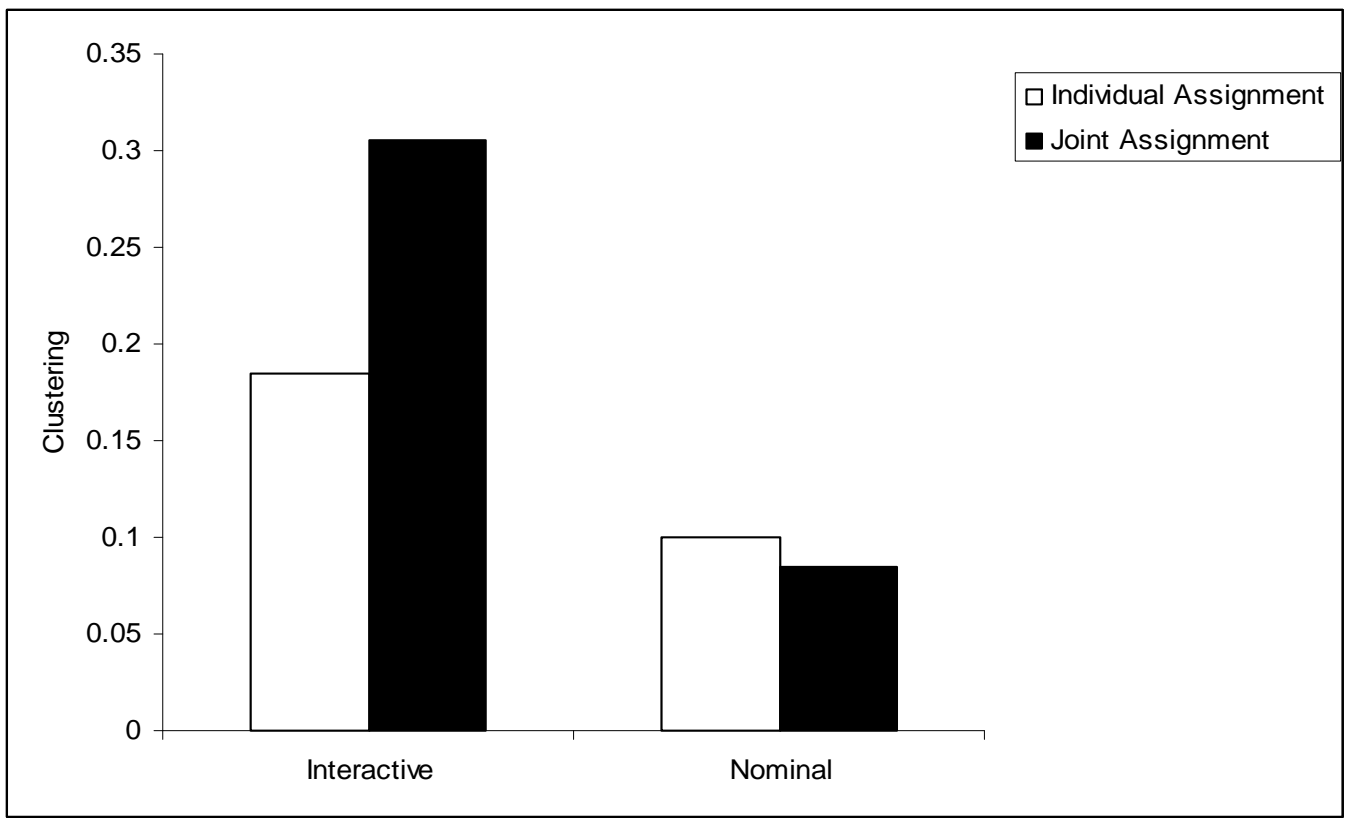

Figure 3. Clustering of ideas as a function of groups and category assignment 


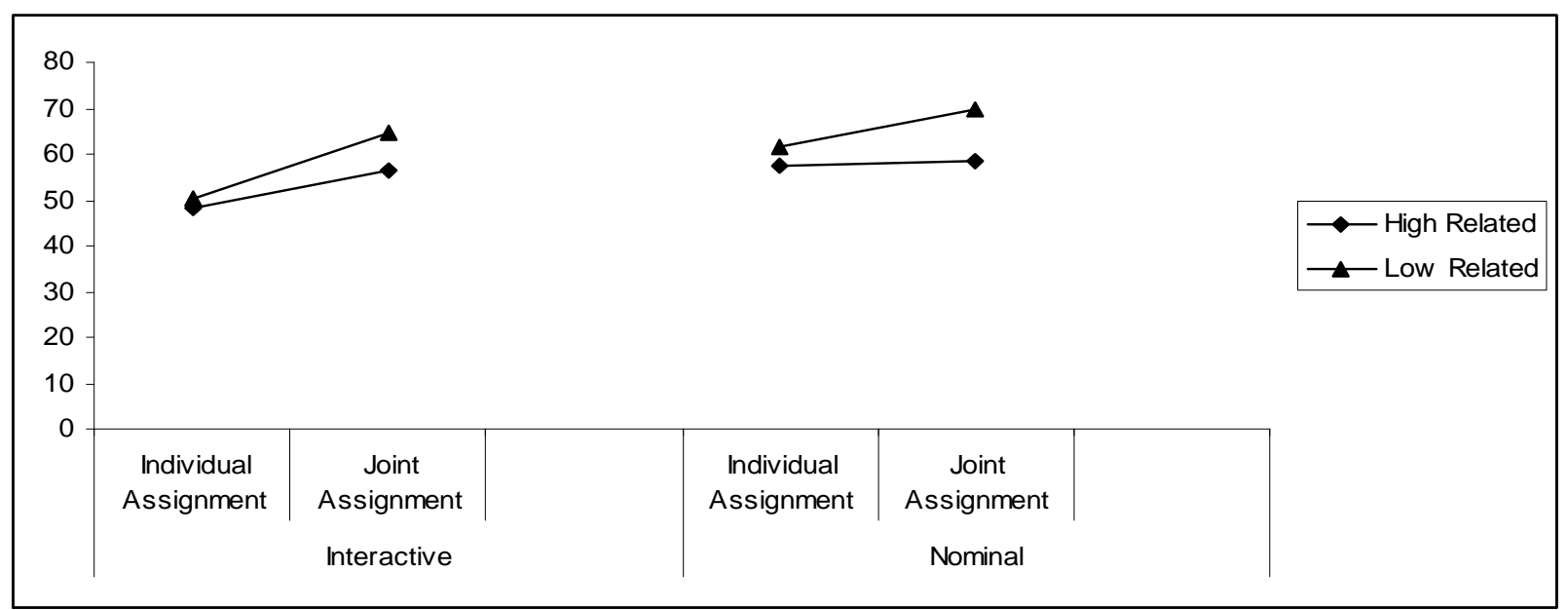

Figure 4. Quantity of ideas for interactive and nominal groups

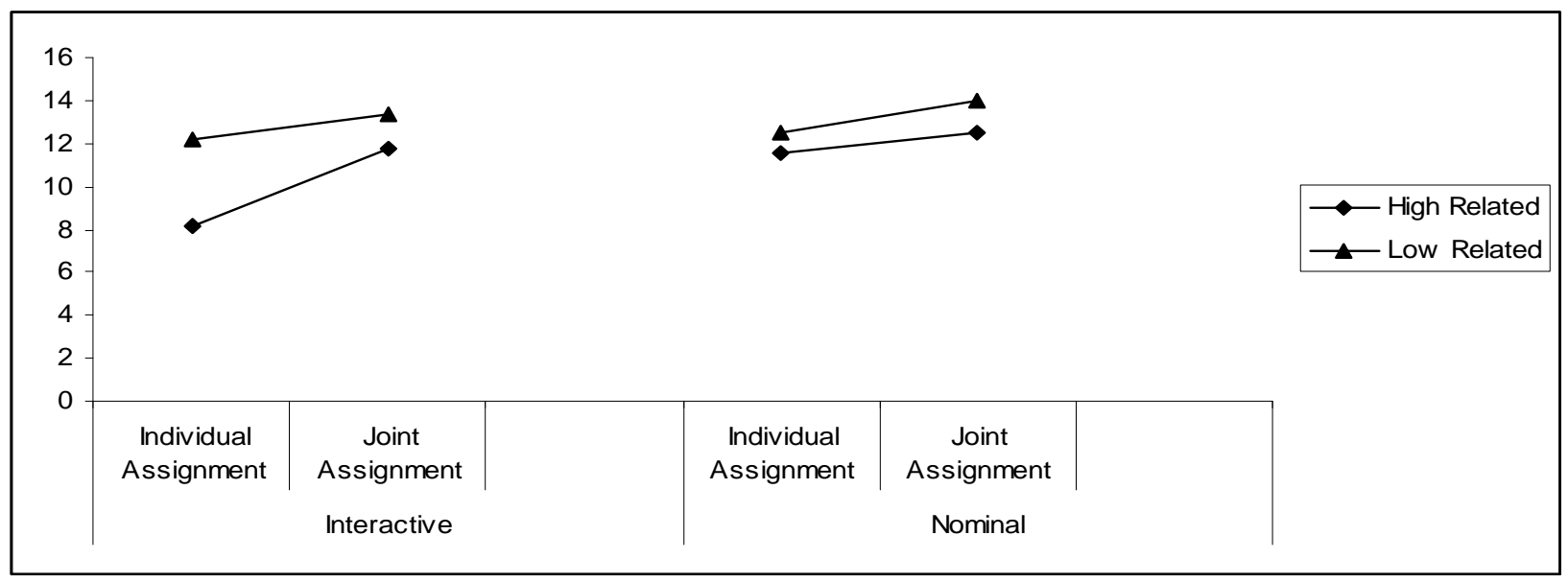

Figure 5. Flexibility for interactive and nominal groups

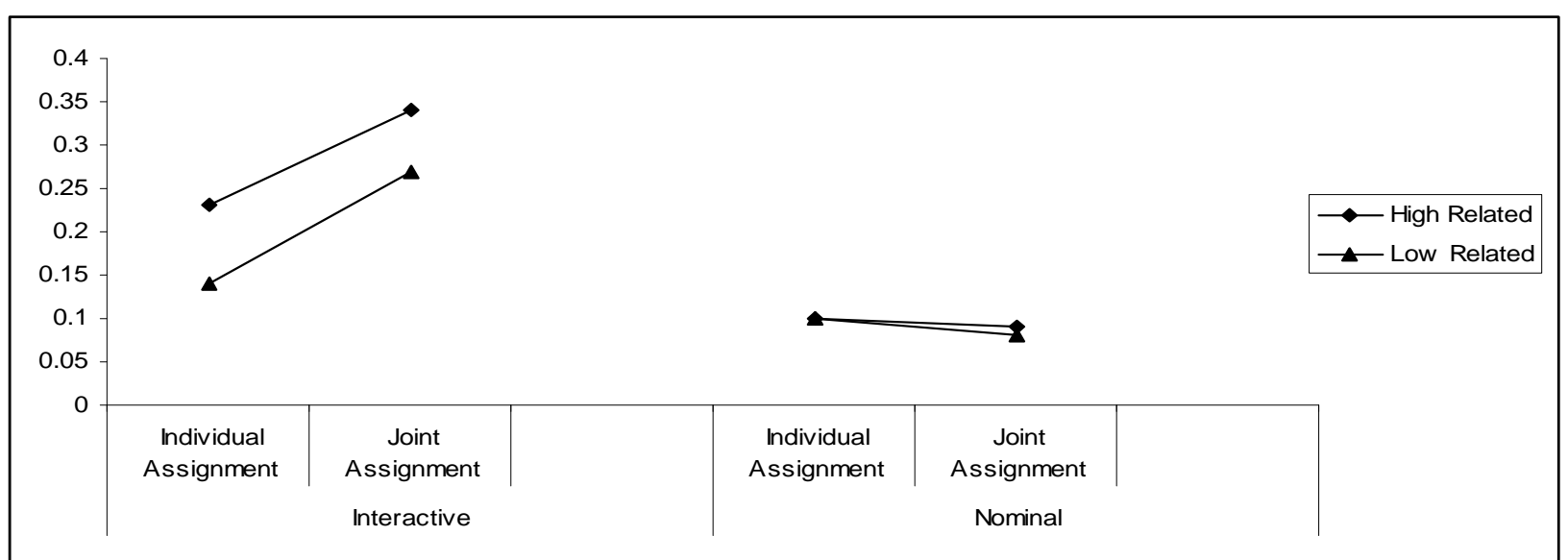

Figure 6. Clustering for interactive and nominal groups 


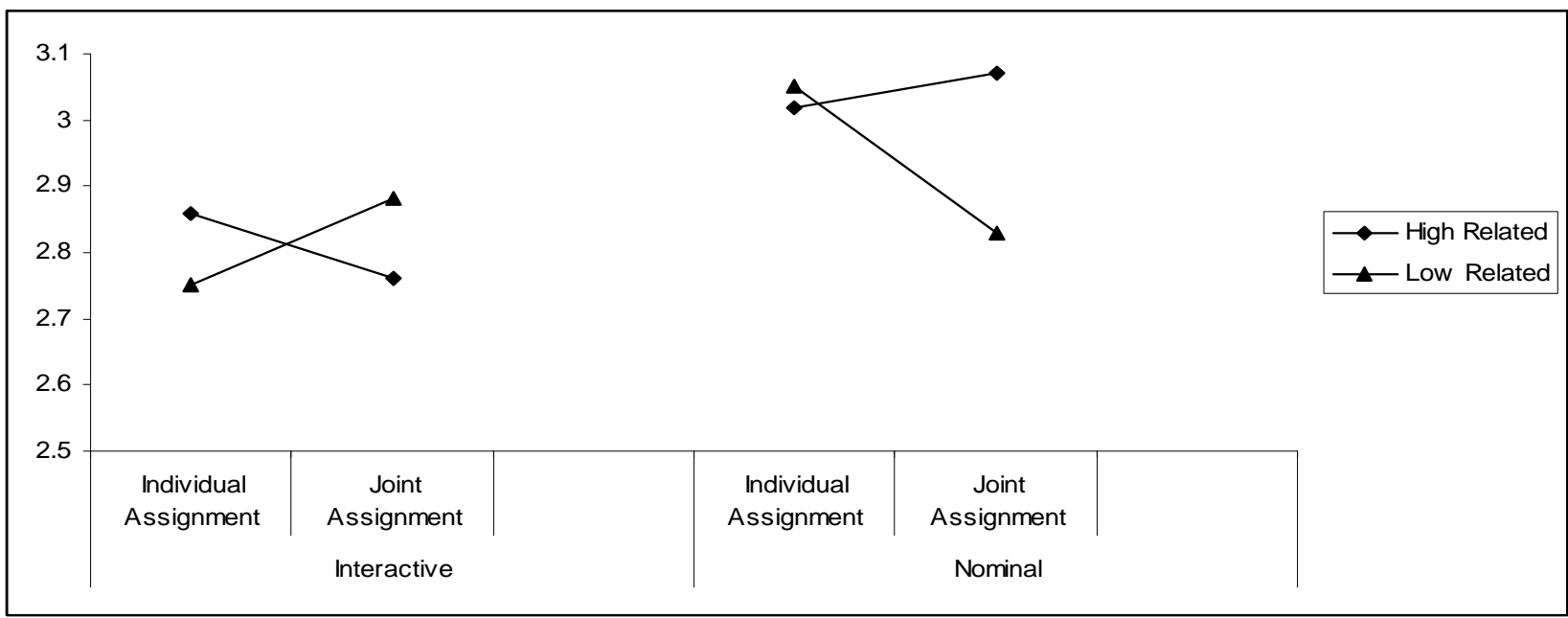

Figure 7. Originality of ideas for interactive and nominal groups

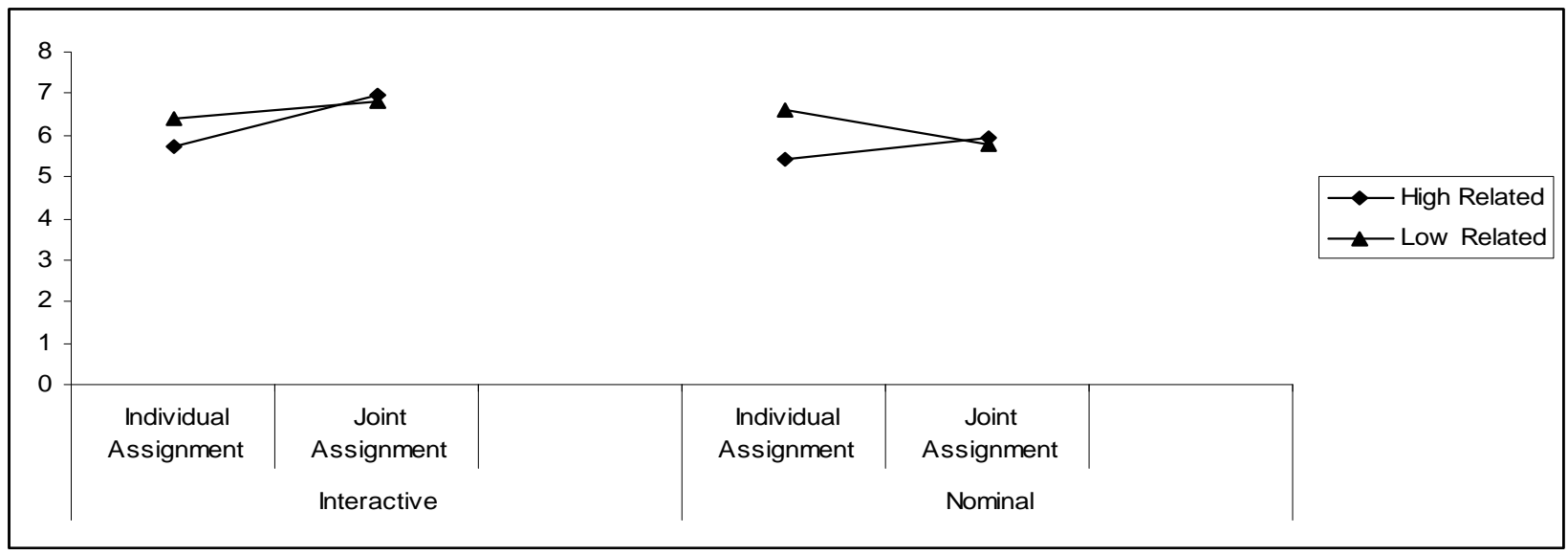

Figure 8. Perceived enjoyment for interactive and nominal groups 
Table 12: Average clustering as a function of type of assignment and category relatedness

\begin{tabular}{lcccc}
\hline Group Type & & $\underline{\text { High Related }}$ & $\underline{\text { Low Related }}$ \\
& Ind. Assign & Joint Assign & Ind. Assign & Joint Assign \\
\hline Interactive & .23 & .34 & .14 & .27 \\
$M$ & .17 & .18 & .14 & .12 \\
$S D$ & & & & \\
Nominal & .10 & .09 & .10 & .08 \\
$M$ & .05 & .03 & .09 & .04 \\
$S D$ & & & & .12 \\
\hline Total & .17 & .22 & .12 & .08 \\
$M$ & 0.11 & .10 & .12 & \\
$(S D)$ & & & & \\
\end{tabular}

\subsubsection{Clustering -with respect to the control group}

A one-way ANOVA was performed only for the interactive-experimental groups and the interactive- control groups. The type of category relatedness did not reach significance. However, a one-way ANOVA revealed a significant effect of type of assignment, $F(2,47)=$ $3.24, p<.05$. Dunnett's test revealed no significant difference between the experimental and the control groups. However, the groups jointly assigned with three categories exhibited higher clustering than groups individually assigned with categories $(M=.12, p<.05)$. There was no significant difference between the joint assignment and no-assignment (control) groups (see figure 9). 


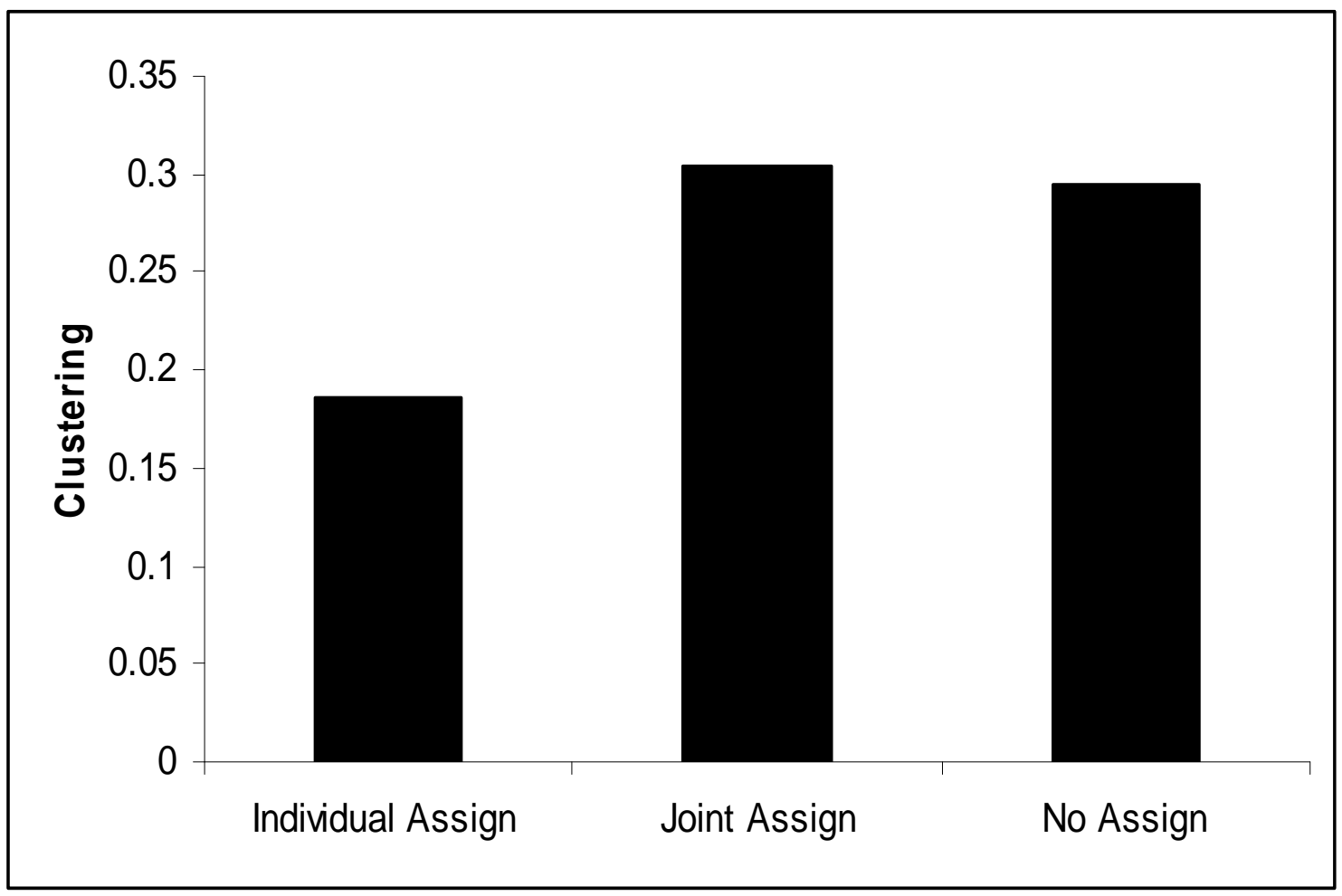

Figure 9. Average clustering for interactive experimental and interactive control groups as a function of type of assignment

\subsubsection{Originality}

A 2(groups) x 2(relatedness) x 2(assignment) between groups ANOVA was performed for average originality of ideas generated. Table 13 shows the average originality of ideas for the type of groups, category relatedness and category assignments. There was a significant main effect of group type, $F(1,72)=12.65, p<.005$. Nominal groups generated ideas of higher average originality $(M=2.99, S D=.20)$ compared to the ideas generated by the interactive groups $(M=2.81, S D=.26)$. However, no significant effect of category assignment and category relatedness was found. There was a significant three way interaction effect for groups, relatedness and assignment, $F(1,72)=6.03, p<.05$ (see figure 10$)$. 
Table 13: Mean originality as a function of type of assignment and category relatedness

Group Type

$\underline{\text { High Related }}$

$\underline{\text { Low Related }}$

Ind. Assign Joint Assign

Ind. Assign Joint Assign

Interactive

$\begin{array}{lcccc}M & 2.86 & 2.76 & 2.75 & 2.88 \\ S D & .28 & .19 & .33 & .22\end{array}$

Nominal

$M$

3.02

3.07

3.05

2.83

$S D$

.23

.21

.13

.17

Total

M

2.94

2.92

2.90

2.86

(SD)

$$
.26
$$

.25

.23

.20

To further investigate the effects of quality in each of nominal and interactive groups separately, a 2(relatedness) x 2(assignment) between group ANOVA was performed for each. No significant effects of category relatedness or category assignment on the quality of ideas generated were found in the interactive groups. For nominal groups, there was a marginally significant effect of category relatedness, $F(1,36)=3.25, p=.08$. The means revealed that the nominal groups generated ideas of higher average originality when they received categories of high relatedness $(M=3.04, S D=.22)$ than when they received categories of low relatedness $(M$ $=2.94, S D=.20$ ). However a significant interaction was found between category relatedness and category assignment in the nominal group condition, $F(1,36)=4.94, p<.05$. The nominal 
groups jointly assigned with three categories of low relatedness generated ideas of lowest average originality $(M=2.83, S D=.17)$ (see figure 8$)$.

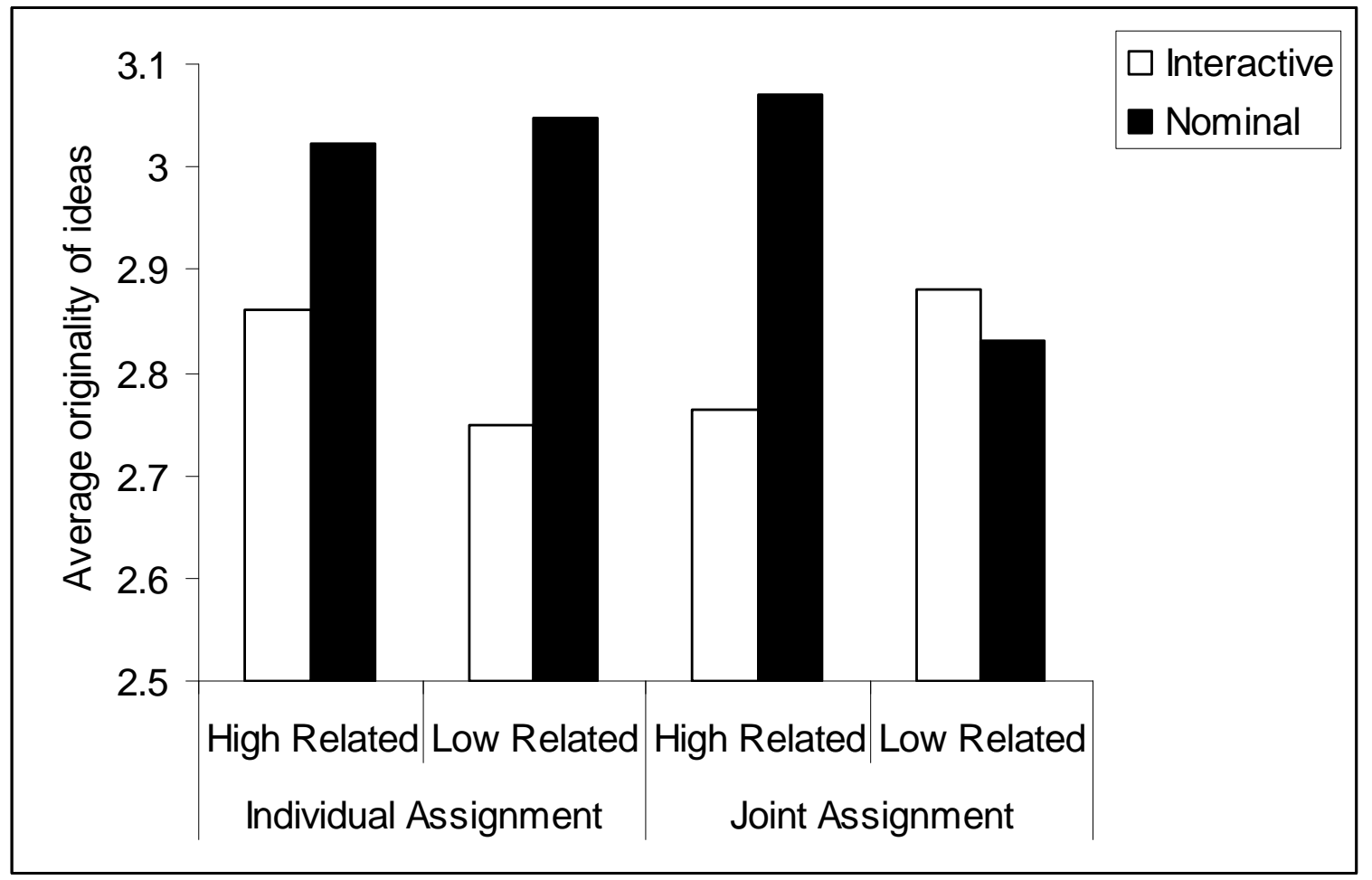

Figure 10. Average originality of ideas as a function of category relatedness, assignment and group condition

\subsubsection{Originality-with respect to the control group}

A one-way ANOVA was performed only for the interactive-experimental groups and the interactive-control groups for average originality of ideas generated. No significant difference was found between the groups. However, a one-way ANOVA for the interactive- experimental and the nominal-experimental groups along with the interactive-control group revealed that there was a significant effect of group condition, $F(2,87)=7.61, p<.005$. Dunnett's test showed that nominal groups generated ideas of higher average originality compared to the control $(M=.17, p$ $<.05)$ and interactive groups $(M=.25, p<.05)$ respectively (see figure 11$)$. 


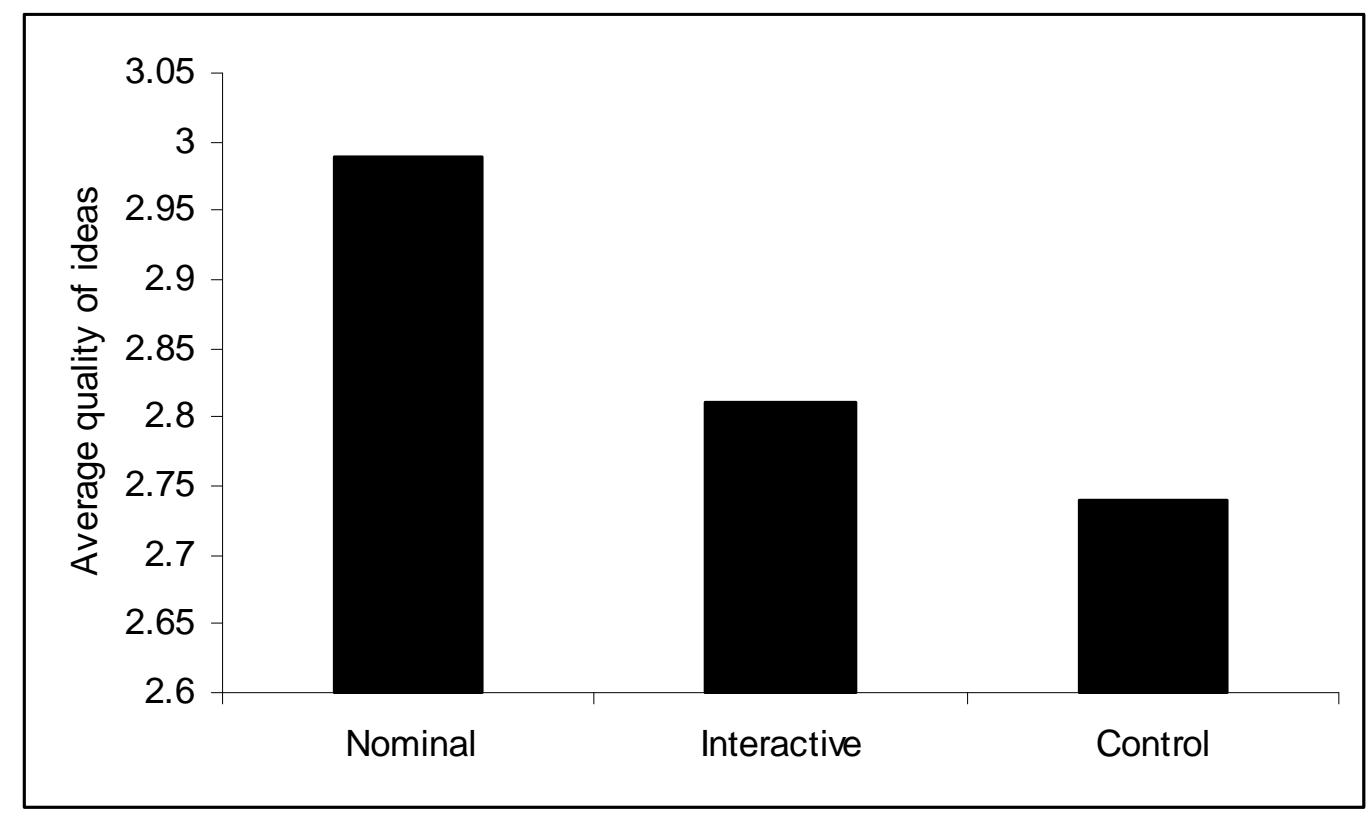

Figure 11. Average originality for experimental interactive and nominal with control

\subsubsection{Perceived Enjoyment}

A 2(groups) x 2(relatedness) x 2(assignment) between groups ANOVA was performed for participants' ratings on the mean perceived enjoyment in the brainstorming session. Table 14 shows the average perceived enjoyment for the type of groups, category relatedness and category assignments. There was a significant main effect of the group type, $F(1,67)=4.13, p<.05$. Participants in the interactive groups reported a higher average enjoyment $(M=6.48, S D=.19)$ in the brainstorming session than the nominal groups $(M=5.93, S D=.19)$ (figure 8$)$. There was also a significant interaction between the type of assignment and the type of category relatedness, $F(1,67)=3.88, p=.05$. The lowest degree of perceived enjoyment was in the individual assignment condition with the assignment of the highly related categories $(M=5.58$, $S D=.28$ ) (see figure 12). In other words, the degree of relatedness did not make much difference in the joint assignment condition, but in the individual assignment condition, individual assignment of highly related categories exhibited the lowest perceived enjoyment. There was 
also a marginally significant interaction effect of the type of assignment and the group condition, $F(1,67)=3.12, p=.08$. The means revealed that the interactive groups with the joint assignment condition enjoyed the brainstorming session the most $(M=6.88, S D=.28)$, whereas the mean enjoyment in the rest of the conditions was more or less at the same level (see figure $13)$.

Table 14: Mean perceived enjoyment as a function of type of assignment and category relatedness

\begin{tabular}{cccccc} 
Group Type & \multicolumn{2}{c}{ High Related } & \multicolumn{2}{c}{ Low Related } \\
& Ind. Assign & Joint Assign & Ind. Assign & Joint A \\
\hline Interactive & 5.75 & 6.96 & 6.4 & 6.8 \\
$M$ & 1.28 & 0.52 & 1.52 & 0.81
\end{tabular}

Nominal

$\begin{array}{lllll}M & 5.37 & 6.02 & 6.60 & 5.80 \\ S D & 1.17 & 0.61 & 1.47 & 1.25\end{array}$

Total

$\begin{array}{lllll}M & 5.54 & 6.46 & 6.5 & 6.3 \\ (S D) & 1.20 & 0.73 & 1.46 & 1.15\end{array}$




\subsubsection{Perceived enjoyment -with respect to the control group}

A one-way ANOVA was performed only for the interactive-experimental groups and the interactive- control groups for perceived enjoyment. No significant difference was found with respect to the control groups.

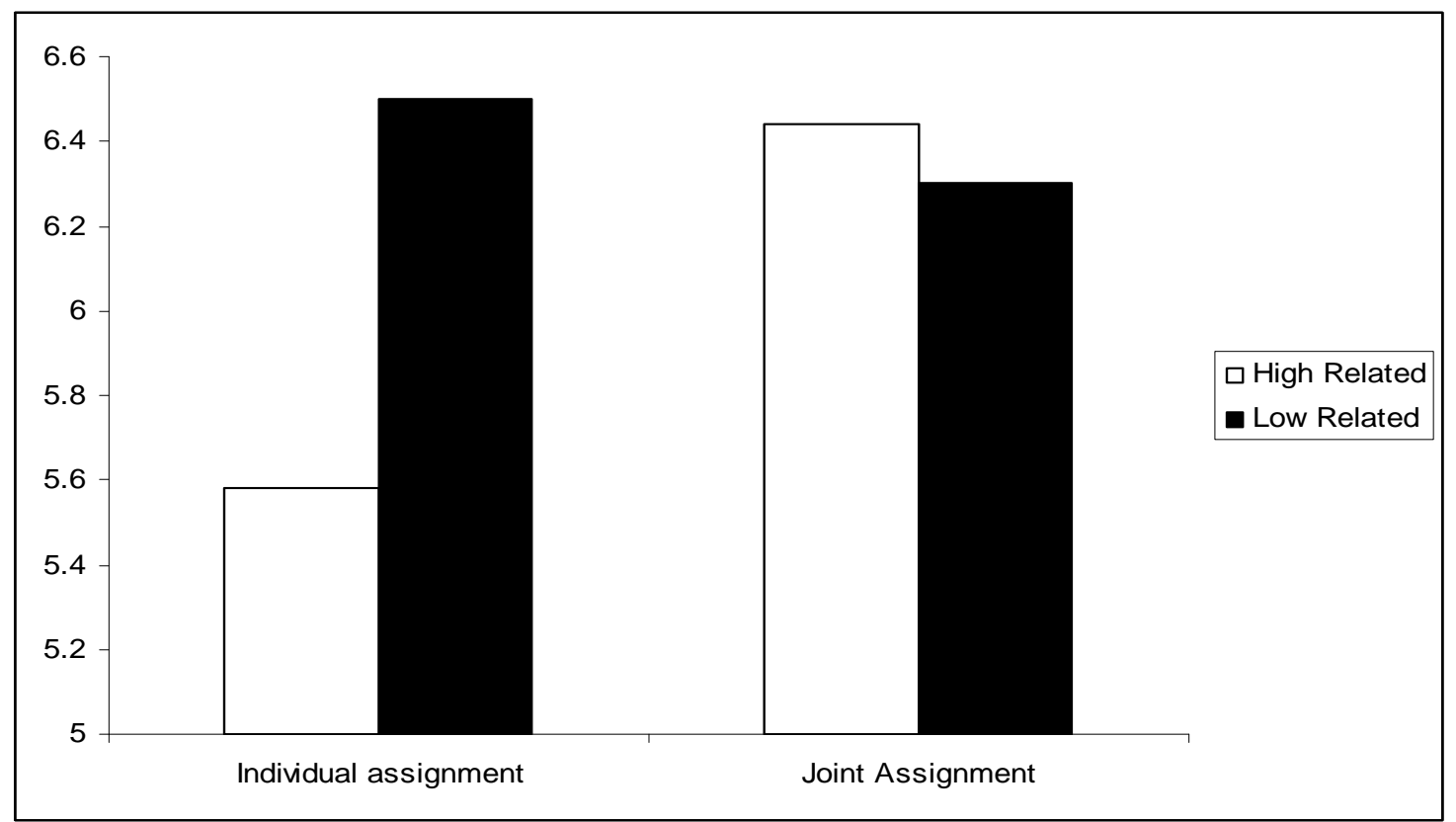

Figure 12. Perceived enjoyment as a function of type of category relatedness and assignment 


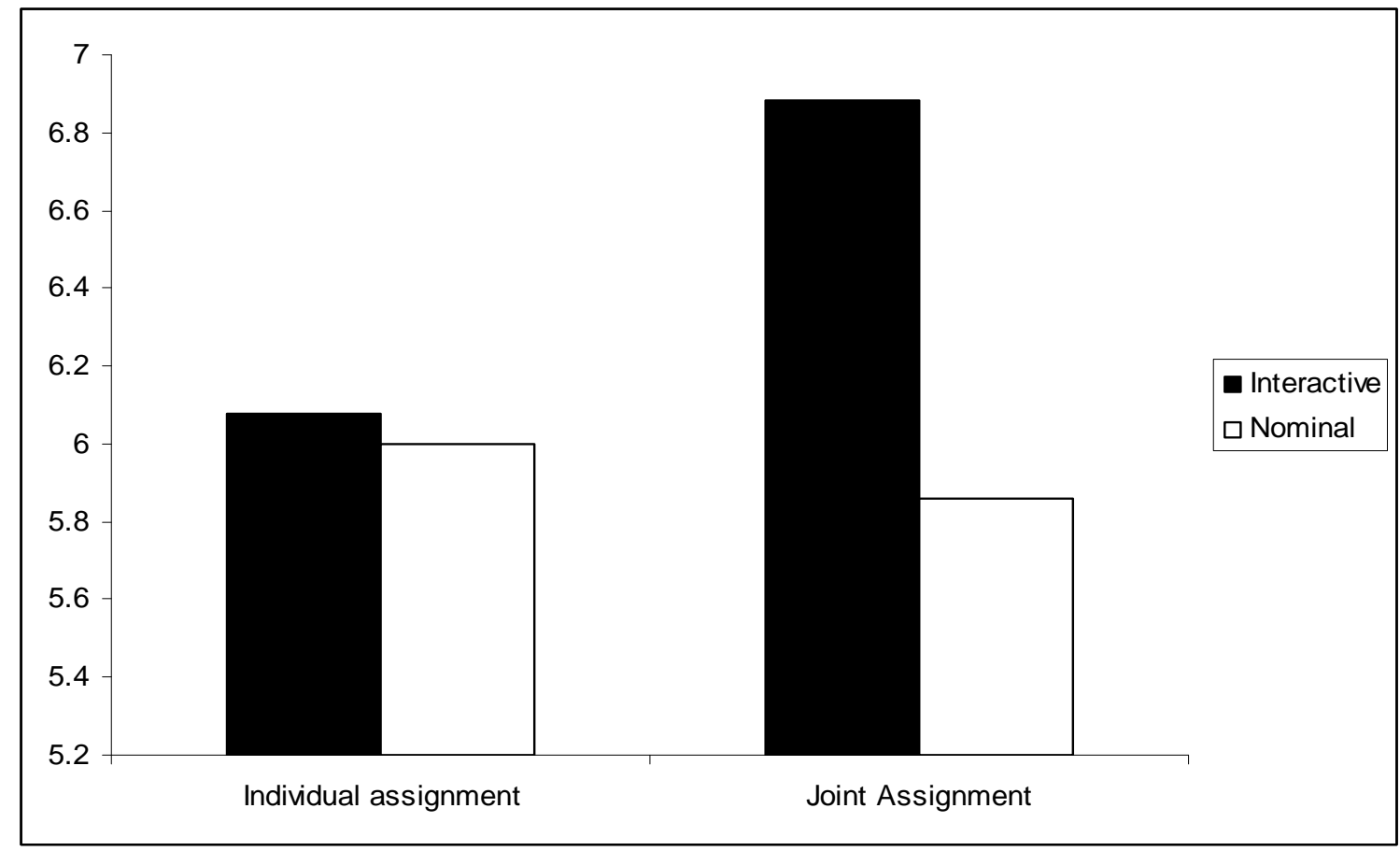

Figure 13. Perceived enjoyment as a function of type of category assignment and group condition 


\section{CHAPTER 6}

\section{DISCUSSION}

The current study investigated the effects of task (category) assignment on the group ideation process in the EBS paradigm. The interactive groups surveyed fewer categories, exhibited high clustering but reported higher perceived enjoyment compared with the nominal groups. The interactive groups also generated fewer ideas than the nominal groups although the difference was marginally significant. Moreover, the clustering exhibited by interactive groups was magnified by the joint assignment condition. Interactive groups also generated ideas of low average originality compared to the nominal groups. However, the nominal groups who were assigned with categories of low relatedness were found to generate ideas of lowest average originality. In terms of type of assignment, groups who were jointly assigned with three categories generated higher quantity of ideas, explored more categories and exhibited higher clustering than the groups who were assigned with individual categories. Among all the groups, the interactive groups with the joint assignment condition showed a marginally significant trend of highest perceived enjoyment. In terms of category relatedness, groups assigned with categories of low relatedness surveyed more categories than those assigned with categories of high relatedness. Moreover, the groups who were individually assigned categories of high relatedness reported the lowest degree of perceived enjoyment. 


\section{$\underline{6.1 \text { Quantity, quality and convergence }}$}

In the current study, the nominal groups did not generate significantly more ideas than the interactive groups. The finding is consistent with the meta-analysis done by DeRosa, Smith and Hantula (2007) which revealed that small e-nominal groups did not differ significantly from the EBS interactive groups in terms of the total number of ideas generated. Similarly Ziegler et al. (2000) also did not find a significant difference between the interactive and the nominal EBS groups in the total number of ideas generated. Previous studies have found that nominal groups of smaller size outperformed the EBS groups (Dennis \& Gallupe, 1993; DeRosa et al. 2007). In contrast, for larger groups (eight or more), EBS groups dramatically outperformed the nominal groups in quality and quantity of ideas generated (c.f. Pinsonneault et al., 1999a). It was argued that EBS interactive groups experience synergy that increases with group size that benefits the larger EBS groups to outperform the nominal groups. Dennis and Williams (2003) reported that the critical size of the "small group" appears to be somewhere in the range of one and three members. The current study found that the difference between three-member nominal and interactive group is marginal in terms of total number of ideas generated. However, Dugosh et al. (2000) found that the EBS groups of four members generated more ideas than the nominal groups of the same size. As the group size of the present study belongs to the critical range proposed by Dennis and Williams (2003), the marginal difference between the interactive and the nominal groups is not surprising. However the nominal groups in the current study outperformed the interactive groups in quality of ideas generated. This finding is consistent with Putman and Paulus (2007) and DeRosa et al. (2007). DeRosa et al. (2007) did a meta-analysis on the effects of the e-nominal brainstorming paradigm on the quality of ideas generated and found 
that the small e-nominal groups produced better quality ideas than small EBS groups, with an effect size ranging from moderate to large.

According to Nijstad \& Stroebe (2006) higher category switching slows down the ideation process as it takes time to search for new categories, thereby leading to lower number of ideas generated. In other words, their model predicts that a higher degree of category switching will be associated with lower number of ideas. However, consistent with Paulus and Brown's (2007) associative memory model, the current study found that flexibility (categories surveyed) was positively associated with the total number of ideas generated. A similar association was also found by the study of Coskun (2005). Also consistent with this perspective is the fact that joint assignment led to a higher number of ideas and categories surveyed compared to the presentation of an individual category.

Some researchers (e.g., Bouchard et al. 1974; Nijstad \& Stroebe, 2006) have reported that a survey of fewer categories may be associated with ideas that are more original. However, the current study did not find such an association. Although the interactive groups as well as the individual assignment condition, led to surveying of fewer categories, the two manipulations did not yield ideas of higher originality. Moreover consistent with past findings (Baruah \& Paulus, 2008; Rietzschel, et al. 2007) the current study also indicates that the relationship between quantity and quality of ideas is relatively complex. In fact, this study found that the total number of ideas was highly correlated with quality of ideas only for interactive groups but not for nominal groups. Maybe in the interactive paradigm, the members take advantage of the combining each other's perspectives which leads to better quality ideas. Future studies should investigate this complex association between the quality and quantity of ideas generated. 
Consistent with previous findings, interactive groups were found to explore fewer categories of ideas (Bouchard, et al., 1974; Larey \& Paulus, 1999; Rietzschel et al., 2007) and exhibited high clustering (Nijstad \& Stroebe, 2006). The convergent orientation of interactive groups was also found in the EBS paradigm by Ziegler et al.(2000). However, the current study further demonstrates that although the interactive groups have a high convergent tendency, instructing the group members to focus on their assigned categories enhances performance.

\section{$\underline{6.2 \text { Effects of category assignment }}$}

The prediction that joint assignment would lead to a higher quantity of ideas and more flexibility than the individual assignment condition was confirmed. In the joint assignment condition, the participants had the opportunity to switch between the categories, which helped them to generate ideas randomly from any of the three categories. In contrast, in case of groups assigned with individual categories, maybe the members felt more accountable to generate ideas from their individually assigned areas, which led to fewer ideas generated.

To further investigate these effects, I analyzed interactive and nominal groups separately. Consistent with my prediction the participants with joint assignment generated more ideas and explored more categories only for interactive groups. A post hoc comparison with control groups (no assignment) revealed that the joint assignment was most beneficial compared to the individual assignment and no assignment condition in terms of the total number of ideas generated. In fact, there was no significant difference between the individual assignment and no assignment group in total ideas generated. For nominal groups no significant effect of category assignment was found.

From the above findings, it is evident that the interactive groups benefit the most from the joint assignment condition. The measure of perceived enjoyment also revealed that the 
interactive groups enjoyed the brainstorming session the most. Moreover, a significant positive correlation was found between perceived enjoyment and flexibility for interactive groups only. Nijstad and Stroebe (2006) reported that the failure of generating further ideas in a brainstorming task is negatively correlated with task enjoyment. Maybe the opportunity of switching categories helped the group members keep generating more and more ideas, which in turn means fewer instances of failure in generating ideas. Thus, fewer failures led to higher enjoyment in the assigned task.

Another point that is evident from the above findings is that the interactive groups benefit more from the assignment of categories. This suggests that interactive groups when provided with examples (categories) become more productive. Smith (2003) reported that when participants are presented with examples, they tend to get fixated to the provided examples leading to low creativity. However, they did not investigate the effects in the interactive paradigm. The current study reveals that the effect of task assignment varies with type of groups. The interactive groups benefit more from such task assignment compared to the nominal groups. Maybe the instruction of task focus helps the groups to pay more attention to their assigned tasks. Research suggests that when individuals are confronted with many alternatives, they tend to avoid making decisions (Chua \& Iyengar, in press). If a similar mechanism is involved in the idea generation process, providing individuals with a more specific task focus may facilitate idea generation. Further research should investigate to what degree such presentation of stimuli is helpful. Will the presentation of 5 categories or exemplars be more beneficial than the presentation of 3 categories or exemplars? Coskun et al. (2000) found that presenting a large number of exemplars (12 exemplars) simultaneously (all at a time) is less beneficial than presenting one exemplar at a time sequentially throughout the brainstorming 
session. However, their study did not investigate how the performance varies based on the number of assigned exemplars in a simultaneous assignment condition.

\section{$\underline{6.3 \text { Effects of category relatedness }}$}

The prediction that low relatedness of categories would lead to the generation of more ideas and survey of more categories was partially supported. The groups assigned with categories of low relatedness surveyed more categories but did not generate more ideas. In the pilot study II, a significant interaction between relatedness and assignment was found in terms of the number of ideas generated. However, in the main study no such interaction was found. The pilot study used a small sample of 4 to 6 groups per condition and the standard deviation differed greatly. Therefore, I attribute this difference of findings to small sample size used in the pilot study.

Consistent with Nijstad et al. (2002), the current study also found that exposure of the groups to low related stimuli led to more surveying of categories. Paulus and Brown (2007) predicted that categories of low relatedness would further prime the low accessible categories, thereby yielding more quantity of ideas. The current study also suggests the possibility of idea generation from the untapped categories. Rietzschel et al. (2007) found that priming dyads with a homogenous topic led to lower productivity compared to priming dyads with heterogeneous topics. However, their study tested the effects in the individual and dyadic paradigm. The current study further investigated the effects in a small group paradigm. The effects of low relatedness were found to be significant only in the interactive group condition. This indicates either that interactive groups take more advantage of low related categories or that the performance of the interactive groups assigned with high related categories is impaired by the high degree of relatedness. Comparison of the low related category and the high related category conditions 
with the control group for flexibility revealed that the low related category groups performed at the same level as control groups, but that the productivity of the highly related category group was the lowest. From this finding one can conclude that highly overlapping knowledge bases are least beneficial in the interactive paradigm. It is possible that the group members were generating ideas only in the overlapping areas of the related categories, leaving the other areas untapped.

In the current study, the separate analyses of the interactive and nominal conditions reveals that the positive effects of low relatedness and joint assignment are present only in interactive group condition. This suggests that the interactive groups have an advantage in such contexts. First, the low relatedness of categories promoted surveying of more categories for such groups. Second, the joint focus on all three categories promoted more surveying of categories as well as exchange of more ideas and perspectives for such groups. This is consistent with the categorization-elaboration model of work group diversity proposed by van Knippenberg, De Drue and Homan (2004). van Knippenberg et al. (2004) proposed that diversity within a group is positively related to the elaboration (group level exchange and integration) of task relevant information and perspectives within the group. This elaboration of task-relevant information and perspectives, in turn, is proposed to be related to group creativity. Paulus and Brown (2007) also argued that because of the associative nature of memory, exchanging ideas and attending to each other's ideas in groups have potentially stimulating effects.

Nijstad et al. (2002) found that in the case of nominal participants, when ideas exchanged are semantically diverse, they increase the range of accessible knowledge and allow for the generation of more diverse ideas. The current study did not find such effects in nominal groups. However in the current study the groups were assigned broad categories instead of ideas (exemplars). This suggests that interactive groups can make the most of priming or presentation 
of categories, possibly due to mutual cognitive stimulation. If cognitive interference was a key factor, nominal groups with three-category assignment should have been most original because their production was not blocked by the ideas of others.

The findings of this study regarding the high positive correlation between category switching and quantity of ideas do not necessarily contradict Nijstad \& Stroebe (2006). Their model predicts that ideation is affected by category changes due to time taken for switching. They tested the individual participants who were assigned with one broad problem area. The methodology of the present study allows one to go beyond previous findings, and the findings show that if specific areas are presented to the participants and the participants are made to focus on the assigned areas, the response latency due to switching may be reduced. Moreover, mutual enhancement should lead to increased performance in the interactive relative to the nominal groups.

This line of reasoning may also explain why Basden et al. (1997) found evidence for cognitive interference in group recall of categorized lists of words, whereas we found no such evidence. In a word recall task, the members have to recall ideas from a list of limited number of ideas. Therefore, the recall of any item from the list reduces the number of remaining items in the list and the list of ideas or categories becomes exhausted quickly. Therefore, the probability is higher that the recall of an idea by one member will interfere with the recall of an idea by another member in the same group. In an idea generation task, especially for broad topics (such as "How to improve your university?"), this is less probable because the number of possible ideas is often quite large. This makes it less likely that the set of available ideas will be exhausted quickly. Thus, cognitive interference is less likely in such groups. Therefore, I argue that in an idea generation task, cognitive stimulation is more likely than a cognitive interference 
effect. Nijstad \& Stroebe (2006) also had similar lines of arguments regarding higher likelihood of cognitive stimulation than interference in interactive groups.

These findings are relevant for multiple areas in the literature. Most notably, the current data adds to the wealth of research investigating the effects of group ideation in diverse and geographically dispersed groups. Specifically groups appear to be more productive when they are instructed to focus on their task. This effect is particularly pronounced when a task is decomposed into parts and the members are instructed to focus on the parts especially in interactive brainstorming groups. As a predictor of number of ideas and divergent orientation, task focus is a valuable addition to the literature in support of cognitive stimulation in brainstorming tasks.

The current data also adds to the research related to the issue of effectiveness of nominal versus interactive brainstorming groups. The effectiveness of nominal and interactive groups seems to differ depending on context. The interactive groups seem to benefit more through task focus. This task focus might have led the interactive groups to engage in more elaboration of task related information. Studies have found that the core positive effects of informational diversity in groups lie in group level exchange, processing, integration of diverse information (cf., Hinsz et al., 1997) and elaboration of task relevant information (van Knippenberg et al., 2004). The nominal groups in the current study did not benefit from such task focus, possibly due to the absence of group level exchange of information.

The current project is also relevant to the research related to informational diversity in groups. Past studies have found that groups having members from different areas of expertise present diverse perspectives in the group discussions (cf., Ancona \& Caldwell, 1992). No studies had investigated the degree of relatedness of members' expertise in the brainstorming groups. 
The current study adds to the existing literature by investigating this degree of relatedness of members' assigned expertise. Specifically this study suggests that members having highly overlapping knowledge base survey few options or alternatives in a group ideation task.

Finally, the current study is a valuable addition to the research related to computermediated groups. This type of brainstorming paradigm minimizes the effects of observable diversity on group productivity. This type of paradigm is important for a clear understanding of the effects of task relevant diversity on the group ideation process. It will be interesting to see how the groups perform in organizations when the members from different parts of the world having different areas of expertise have to interact electronically. It will also be interesting to see how the performance of the groups varies with the type of problems assigned.

One limitation of the current study is that it used college students as participants. Future studies should investigate the effects of task focus for different age groups. Maybe the task focus and the sense of accountability will vary with different age groups. Another limitation could be the use of computer-mediated communication by these student participants. Certain factors that could affect their performance in this paradigm are their typing speed, familiarity with the computer chat tools, etc. Some participants may need extra physical and cognitive efforts to type, which may divide their cognitive attention on keyboarding and the computer screen resulting in slow ideation process. 


\section{APPENDIX A}

\section{BACKGROUND QUESTIONNAIRE}


Participant no. :

Please answer the following questions about yourself :

1. Age

2. Gender: Male Female

3. Country of birth

4. What is your country of citizenship?

5. What is your native language?

6. What other languages do you speak?

7. What is your major?

8. What is your ethnicity?

9. Do you have a job? If yes, what is it?

10. What are your hobbies? 
APPENDIX B

RULES FOR THE INTERACTIVE GROUPS 
Brainstorming is a form of group interaction, which is used to facilitate the flow of ideas. It is widely used in a large number of US corporations and is generally used when new, unique, original and creative ideas are desired. It is not used to solve everyday problems. The procedure is relatively straight forward and easy to comprehend. The following rules are for brainstorming in groups. We want you to apply these rule as best as you can while working as a group.

1. Criticism is ruled out. Adverse judgment of ideas must be withheld. Say everything you think of.

2. Freewheeling is welcome. The wilder the idea the better. It is easier to tame down than to think up. Do not be afraid to say anything that comes to mind. The further out the idea the better. This will stimulate more and better ideas.

3. Quantity is wanted. The greater the number of ideas the more likelihood of winners. Come up with as many as you can.

4. Combination and improvement are sought. You should try to suggest how ideas of others could be joined or changed into still better ideas. Do not be afraid to combine and improve on them.

5. Stay focused on the task. Concentrate on the problem at hand and avoid engaging in irrelevant thought processes and discussions.

6. Do not tell stories. We are only interested in your ideas. Do not tell stories about their experiences.

7. Do not explain ideas. Do not expand ideas on why you think something is good or bad. Simply state your idea and continue with next ideas. 


\section{APPENDIX C}

RULES FOR THE NOMINAL GROUPS 
Brainstorming is a form of ideation process, which is used to facilitate the flow of ideas. It is widely used in a large number of US corporations and is generally used when new, unique and original ideas are desired. It is not used to solve everyday problems. The procedure is relatively straightforward and easy to comprehend.

The following rules are for brainstorming in isolation. We want you to apply these rules as best as you can while working alone on a task.

\section{Say everything you think of.}

2. Freewheeling is welcome. The wilder the idea the better. It is easier to tame down than to think up. Do not be afraid to say anything that comes to mind. The further out the idea the better. This will stimulate more and better ideas.

3. Quantity is wanted. The greater the number of ideas the more likelihood of winners. Come up with as many as you can.

4. Combination and improvements are sought. You should be able to suggest how ideas can be joined or changed into still better ideas. Do not be afraid to combine and improve on them.

5. Stay focused on the task. Concentrate on the problem at hand and avoid engaging in irrelevant thought processes and discussions.

a. Do not tell stories. We are only interested in your ideas. Do not tell stories about your experiences.

b. Do not explain ideas. Do not expand on why you think something is good or bad. Simply state your idea and continue with the next ideas. 
APPENDIX D

INSTRUCTIONS FOR CATEGORY ASSIGNMENT (INTERACTIVE) 
You will type ideas on the computer and share these with one another. You will type one idea on the computer at a time and press Enter to send it out. You will be able to see everyone's ideas on the screen as they are sent. Read these ideas as they come and add your own ideas and send them out. This will continue until the session is over. You do not need to make complete sentences when typing the ideas. Just use simple phrases. Do not worry about spelling or grammar.

Research has shown that paying careful attention to the ideas that are generated by the others stimulates people to come up with more and better ideas. You will be asked to recall and discuss the ideas generated by others at the end of the session. 
APPENDIX E

INSTRUCTIONS FOR CATEGORY ASSIGNMENT (NOMINAL) 
You will type ideas on the computer on a given problem. You will type one idea on the computer at a time and press Enter to send it out. You will be able to see your ideas on the screen as you send them. Read these ideas, add more ideas and send them out. This will continue until the session is over. You do not need to make complete sentences when typing the ideas. Just use simple phrases. Do not worry about spelling or grammar.

Research has shown that paying careful attention to the ideas stimulates people to come up with more and better ideas. You will be asked to recall the ideas generated by yourself at the end of the session. 
APPENDIX F

INSTRUCTIONS FOR INDIVIDUAL ASSIGNMENT (INTERACTIVE) 
The problem you will be working on today is called "the UTA problem". Basically we would like you to generate ideas or ways to improve UTA. Any suggestions you have about how to make UTA better are appropriate.

Each of you will be assigned a different broad topic that is directly related to UTA problem. That is, each of you will have your own unique topic for which you will have primary responsibility. Please generate as many ideas as you can on your assigned topic, but feel free to express any other ideas about improving UTA that may occur to you.

You will have 15 minutes to work on the problem. 


\section{APPENDIX G}

INSTRUCTIONS FOR JOINT ASSIGNMENT (INTERACTIVE) 
The problem you will be working on today is called "the UTA problem". Basically we would like you to generate ideas or ways to improve UTA. Any suggestions you have about how to make UTA better are appropriate.

Your group will be assigned 3 broad topics that are directly related to UTA problem. That is, each of you will have the same three topics for which you will have primary responsibility. Please generate as many ideas as you can on the assigned topics, but feel free to express any other ideas about improving UTA that may occur to you.

You will have 15 minutes to work on the problem. 
APPENDIX H

INSTRUCTIONS FOR INDIVIDUAL ASSIGNMENT (NOMINAL) 
The problem you will be working on today is called "the UTA problem". Basically we would like you to generate ideas or ways to improve UTA. Any suggestions you have about how to make UTA better are appropriate.

You will be assigned a broad topic that is directly related to the UTA problem. That is, each of you will have your own unique topic for which you will have primary responsibility. Please generate as many ideas as you can on your assigned topic, but feel free to express any other ideas about improving UTA that may occur to you.

You will have 15 minutes to work on the problem. 


\section{APPENDIX I}

INSTRUCTIONS FOR JOINT ASSIGNMENT (NOMINAL) 
The problem you will be working on today is called "the UTA problem". Basically we would like you to generate ideas or ways to improve UTA. Any suggestions you have about how to make UTA better are appropriate.

Your group will be assigned 3 broad topics that are directly related to the UTA problem. That is, each of you will have the same three topics for which you will have primary responsibility. Please generate as many ideas as you can on the assigned topics, but feel free to express any other ideas about improving UTA that may occur to you.

You will have 15 minutes to work on the problem. 
APPENDIX J

EXPERTISE ASSIGNMENT FORM 
Please check the category that suits you the most in terms of your major, areas of interest, knowledge or expertise:

Your areas of expertise

1. BIOLOGY

$\mathrm{O}$

2. PSYCHOLOGY

$\mathrm{O}$

3. NURSING

$\mathrm{O}$

4. BUSINESS

$\mathrm{O}$

5. ARTS

a. Fine Arts

$\mathrm{O}$

b. Martial Arts

$\mathrm{O}$

6. ARCHITECTURE

$\mathrm{O}$

7. CRIMinOlOGY

$\mathrm{O}$

8. FINANCE / ACCOUNTS

$\mathrm{O}$

9. GAMES / SPORT

$\mathrm{O}$

10. MUSIC

$\mathrm{O}$

11. TRANSPORT / COMMUNICATION

$\mathrm{O}$

12. EDUCATION

$\mathrm{O}$

13. TECHNOLOGY

$\mathrm{O}$

14. FOOD

$\mathrm{O}$

15. SOCIAL WELFARE

$\mathrm{O}$ 
APPENDIX K

POST EXPERIMENT QUESTIONNAIRE (INTERACTIVE GROUPS) 
Please answer the following questions concerning various aspects of your experience while participating in the experiment. The following scales are provided for you to indicate your responses. The more extreme you feel in one direction or another, the more you should mark a number in that direction.

1. Were you instructed that you were responsible for brainstorming on one or on three topics? one topic three topics

2. How different were the types of ideas you generated about your topic or topics and those generated by others about their topic or topics?

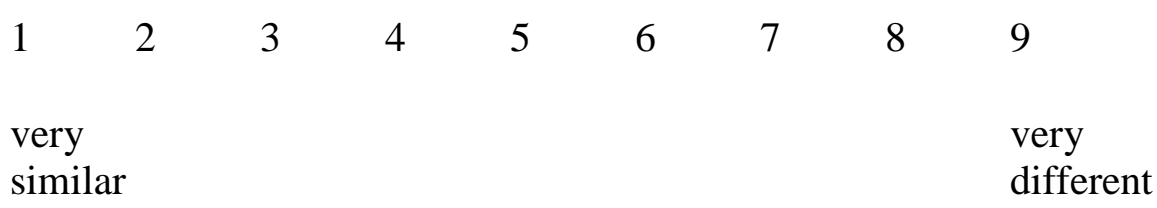

3. How much was your idea generation process hindered by your attention to others' ideas?

$\begin{array}{lllllllll}1 & 2 & 3 & 4 & 5 & 6 & 7 & 8 & 9\end{array}$

not at very much

all

4. How much was your idea generation process stimulated by your attention to others' ideas?

$\begin{array}{lllllllll}1 & 2 & 3 & 4 & 5 & 6 & 7 & 8 & 9\end{array}$

not at very much

all 
5. How would you rate the number of ideas you generated while brainstorming?

\begin{tabular}{|c|c|c|c|c|c|c|c|}
\hline 1 & 2 & 3 & 4 & 5 & 6 & 7 & 8 \\
\hline $\begin{array}{l}\text { very } \\
\text { few }\end{array}$ & & & & & & & \\
\hline
\end{tabular}

6. How would you rate the quality of ideas you generated while brainstorming-

$\begin{array}{lllllllll}1 & 2 & 3 & 4 & 5 & 6 & 7 & 8 & 9 \\ \text { very } & & & & & & & & \text { very } \\ \text { few } & & & & & & & & \\ \text { many }\end{array}$

7. How much did you enjoy the brainstorming session?

$\begin{array}{lllllllll}1 & 2 & 3 & 4 & 5 & 6 & 7 & 8 & 9 \\ \text { not at } & & & & & & & & \text { very } \\ \text { all } & & & & & & & & \\ & & & & & & & & \end{array}$

8. How much did you build upon other's ideas?

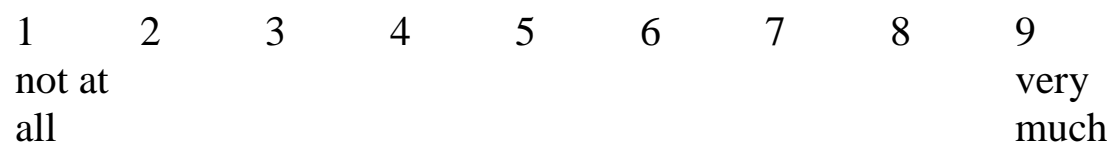

9. How much did you attend to others' ideas?

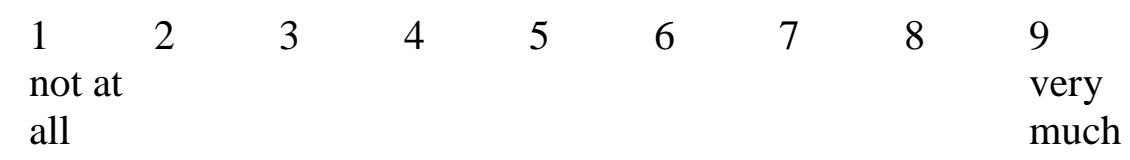

10. Please indicate if there is anything specific or in general that prompted you to work harder or generate more ideas. 
APPENDIX L

\section{DESIGN OF THE MAIN STUDY}




\begin{tabular}{|l|l|l|l|}
\hline & & Individual & Group assignment \\
& & assignment & \\
\hline Interactive & High related & & \\
& & & \\
\cline { 2 - 4 } & Low related & & \\
\hline Nominal & High related & & \\
\cline { 2 - 4 } & & & \\
\cline { 2 - 4 } & Low related & & \\
& & & \\
\hline
\end{tabular}




\section{APPENDIX M}

\section{CATEGORIES ASSIGNED}




\section{HIGH IN RELATEDNESS}

Teachers

Classes

Technologies

Student-welfare

Campus- activities

Campus-safety

Buildings

Campus beautification

Addition/construction/renovation

Buildings

Classes

Technologies

\section{LOW IN RELATEDNESS}

Teachers

Campus beautification

Campus-safety

Classes

Campus activities

Addition/construction/renovation

Technology

Student-welfare

Campus beautification

Buildings

Campus-safety

Teachers 
APPENDIX N

CATEGORIES USED FOR RELATEDNESS RATINGS 
Below there are several areas that one can improve on to raise the standard of UT Arlington. Please read and think about each set of areas carefully. Once you have thought about each set of areas consider the degree to which the areas are related to each other. Then choose the answer option from the scale below to rate each statement.

\begin{tabular}{|c|c|c|c|c|}
\hline $\begin{array}{l}\text { Totally } \\
\text { unrelated }\end{array}$ & $\begin{array}{l}\text { Moderately } \\
\text { unrelated }\end{array}$ & $\begin{array}{l}\text { Somewhat } \\
\text { related }\end{array}$ & $\begin{array}{l}\text { Moderately } \\
\text { related }\end{array}$ & $\begin{array}{l}\text { Highly } \\
\text { related }\end{array}$ \\
\hline SERIAL NO. & CATEGORY 1 & CATEGORY 2 & CATEGORY 3 & $\begin{array}{l}\text { RATING } \\
(1 \text { TO 5) }\end{array}$ \\
\hline 1 & TEACHERS & CLASSES & TECHNOLOGIES & \\
\hline 2 & STUDENT-WELFARE & CAMPUS-ACTIVITIES & PARKING & \\
\hline 3 & BUILDINGS & CAMPUS BEAUTIFICATION & $\begin{array}{l}\text { ADDITION/CONSTRUCTION/ } \\
\text { RENOVATION }\end{array}$ & \\
\hline 4 & TEACHERS & BUILDINGS & PARKING & \\
\hline 5 & CLASSES & CAMPUS ACTIVITIES & $\begin{array}{l}\text { ADDITION/CONSTRUCTION/ } \\
\text { RENOVATION }\end{array}$ & \\
\hline 6 & TECHNOLOGY & STUDENT-WELFARE & CAMPUS BEAUTIFICATION & \\
\hline 7 & TEACHERS & STUDENT-WELFARE & BUILDINGS & \\
\hline 8 & CLASSES & CAMPUS-ACTIVITIES & CAMPUS BEAUTIFICATION & \\
\hline 9 & BUILDINGS & CAMPUS ACTIVITIES & STUDENT-WELFARE & \\
\hline 10 & TECHNOLOGIES & PARKING & $\begin{array}{l}\text { ADDITION/CONSTRUCTION/ } \\
\text { RENOVATION }\end{array}$ & \\
\hline 11 & TEACHERS & CAMPUS-ACTIVITIES & $\begin{array}{l}\text { ADDITION/CONSTRUCTION/ } \\
\text { RENOVATION }\end{array}$ & \\
\hline 12 & PARKING & $\begin{array}{l}\text { ADDITION/CONSTRUCTION/ } \\
\text { RENOVATION }\end{array}$ & CAMPUS BEAUTIFICATION & \\
\hline 13 & BUILDINGS & CLASSES & TECHNOLOGIES & \\
\hline 14 & CAMPUS BEAUTIFICATION & TECHNOLOGIES & STUDENT-WELFARE & \\
\hline 15 & PARKING & TEACHERS & CLASSES & \\
\hline
\end{tabular}


APPENDIX O

POST EXPERIMENTAL QUESTIONNAIRE (NOMINAL GROUPS) 
Post experiment questionnaire:

Participant no.

Please answer the following questions concerning various aspects of your experience while participating in the experiment. The following scales are provided for you to indicate your responses. The more extreme you feel in one direction or another, the more you should mark a number in that direction.

1. Were you instructed that you were responsible for brainstorming on one or on three topics? one topic

three topics

2. How would you rate the number of ideas you generated while brainstorming?

$\begin{array}{lllllllll}1 & 2 & 3 & 4 & 5 & 6 & 7 & 8 & 9 \\ \text { very } & & & & & & & & \text { very } \\ \text { few } & & & & & & & & \text { many }\end{array}$

3. How would you rate the quality of ideas you generated while brainstorming-

$\begin{array}{lllllllll}1 & 2 & 3 & 4 & 5 & 6 & 7 & 8 & 9 \\ \text { very } & & & & & & & & \text { very } \\ \text { few } & & & & & & & & \text { many }\end{array}$

4. How much did you enjoy the brainstorming sessions?

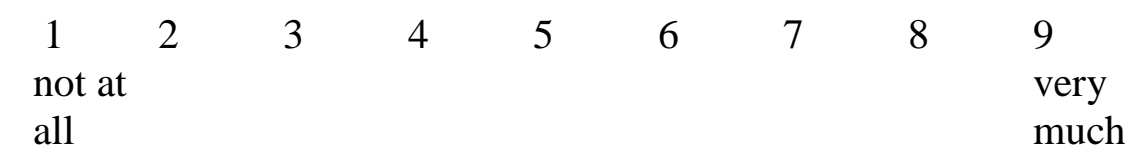

5. How much did you build on your ideas?

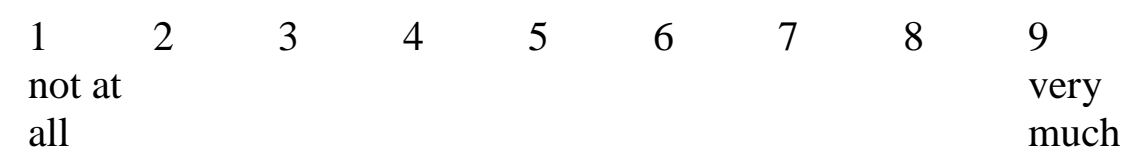

6. Please indicate if there is anything specific or in general that prompted you to work harder or generate more ideas. 
APPENDIX P

CATEGORIES USED FOR IDEA RATINGS 


\begin{tabular}{|c|c|c|}
\hline CATEGORY & CODE & DESCRIPTION \\
\hline FOOD & FD & RELATED TO FOOD, RESTAURANT,FOOD VENDING MACHINE,BAR, DRINKS \\
\hline FINANCIAL AID & FID & SCHOLARSHIP,TUITION, FINANCIAL AID \\
\hline $\begin{array}{l}\text { ADDITION/CONSTRUCTIO } \\
\text { N/RENOVATION }\end{array}$ & ACR & NEW ADDITION/CONSTRUCTION/RENOVATION OF ROOM, BUIDINGS,ROADS,ETC. \\
\hline TEACHER & TEA & TEACHER,TEACHING, LECTURES \\
\hline CAMPUS SAFETY & CSF & COPS, CAMPUS SECURITY, TELEPHONE BOOTHS, MORE LIGHTS, ETC. \\
\hline DEPARTMENT & DPT & $\begin{array}{l}\text { GRE SCORE, ADMISSIONS, BURSERS, REGISTRATION, MAV IDS, COURSE WAIVER, } \\
\text { TRANFER }\end{array}$ \\
\hline HEALTH & HLT & $\begin{array}{l}\text { UTA MEDIACAL STORE, STUDENT INSURANCE, CLEANLINESS, SENITATION, TRASH, } \\
\text { RESTROOMS }\end{array}$ \\
\hline SPECIAL POPULATION & SPP & $\begin{array}{l}\text { STUDENT MOMS, DAY CARE, HANDICAPS, ELDERLY PEOPLE, NUDIST COLONY, } \\
\text { ALIENS, ETC. }\end{array}$ \\
\hline CLASSES & CLS & BOOKS,BOOKSTORE,CLASSROOM TEMPERATURE,CLASS SIZE, NEW COURSES \\
\hline TECHNOLOGY & $\mathrm{TCH}$ & $\begin{array}{l}\text { COMPUTER,PRINTER,OVERHEAD, LAB EQUIPMENTS, EXERCISE MACHINES, } \\
\text { ANYTHING RELATED TO TECHNOLOGY }\end{array}$ \\
\hline PARKING & PRK & PARKING,PARKING TICKETS,STICKERS,GARAGES,ETC. \\
\hline TRANSPORTATION & TPT & $\begin{array}{l}\text { SHUTTLE,TRANPORTATION, MAPS, SIGNS, GOLFCARTS, ELEVATORS, ESCALATORS, } \\
\text { ETC. }\end{array}$ \\
\hline CAMPUS ACTIVITIES & CAT & $\begin{array}{l}\text { INVITING CELEBRITIES, GAMES \& SPORTS, CULTURAL ACTIVITIES, SHOWS } \\
\text { CONFERENCES,SEMINARS, ETC. }\end{array}$ \\
\hline LIBRARY & LIB & RELATED TO LIBRARY \\
\hline STUDENT WALFARE & SWF & $\begin{array}{l}\text { STUDENT'S EMPLOYMENT,WORK STUDY, ADVICE/COUNSELLING, ANYTHING } \\
\text { SPECIAL FOR COMMUTER, HOMECOMING }\end{array}$ \\
\hline BUILDINGS & BLD & BUILDINGS, DORMS, RESTROOMS \\
\hline CAMPUS BEAUTY & CBT & $\begin{array}{l}\text { ANYTHING TO ENHANCE THE INNER/OUTER BEAUTY OF CAMPUS, PAINTS, } \\
\text { DECORATIVES, DESIGNS,ARCHITECT, PLANTS, STONES,ETC. }\end{array}$ \\
\hline $\begin{array}{l}\text { ADVERTISEMENTS/ } \\
\text { PUBLICITY }\end{array}$ & ADP & ADVERTISEMENTS AND PUBLICITY RELATED TO UTA. \\
\hline
\end{tabular}




\section{REFERENCES}

Amabile, T. M. (1996). Creativity in context: Update to the social psychology of creativity. Boulder, CO: Westview Press.

Ancona, D. G. \& Caldwell, D. F. (1992). Demography and design: Predictors of new product team performance. Organization Science, 3, 321-341.

Anson, R., Bostrom, R., \& Wynne, B. (1995). An experiment assessing group support system and facilitator effects on meeting outcomes. Management Science, 41 (2), 189-208.

Armstrong, J. S., Denniston, W. B. \& Gordon, Matt M.(1975). The use of the decomposition principle in making judgments. Organizational Behavior and Human Performance, $14(2), 257-263$.

Bantel, K. A. \& Jackson, S. E. (1989). Top management and innovations in banking: does the composition of the team make a difference? Strategic Management Journal.10, 107-124.

Baruah, J. \& Paulus, P. B. (2008). Effects of training on idea-generation in groups. Small Group Research.

Basden, B. H., Basden, D. R., Bryner, S. \& Thomas III, R. L. (1997). A comparison of group and individual remembering: Does collaboration disrupt retrieval strategies? Journal of Experimental Psychology, 23(5), 1176-1189.

Baughman, W. A., \& Mumford, M. D. (1995). Process-analytic models of creative capacities: Operations influencing the combination-and-reorganization process. Creativity Research Journal, 8(1), 37-62. 
Beck-Jones, J. J. (2004). The effect of cross-training and role assignment in cooperative learning groups on task performance, knowledge of accounting concepts, teamwork behavior, and acquisition of interpositional knowledge. Dissertation Abstract International. 64(7), 2378.

Bouchard, T. J., Drauden, G.\& Barsaloux, J. (1974). A comparison of individual, subgroup, and total group methods of problem solving. Journal of Applied Psychology, 59(2), 226-227.

Bowers, C., Pharmer, J. A., \& Salas, E. (2000). When member homogeneity is needed in work teams: a meta-analysis. Small Group Research, 31, 305-327.

Brown, V., \& Paulus P. B. (2002). Making group brainstorming more effective: Recommendations from an associative memory perspective. Current Directions in Psychological Science, 11, 208-212.

Brown, V., Tumeo, M., Larey, T. S., \& Paulus, P. B. (1998) Modeling cognitive interactions during group brainstorming. Small Group Research, 29, 495-526.

Byrne, D. (1961). Interpersonal attraction and attitude similarity. The Journal of Abnormal and Social Psychology, 62(3), 713-715.

Byrne, D. (1971). The ubiquitous relationship: Attitude similarity and attraction: A cross-cultural study. Human Relations, 24(3), 201-207.

Chaffin, R. \& Herrmann, D. J. (1987) . Relation element theory: A new account of the representation and processing of the semantic. In D. Gorfien \& r. Hoffman (Eds.), Memory and Learning:The Ebbinghaus Centennial Conference, Hillsdale,NJ : Erlbaum.

Chua, R. Y-J. \& Iyengar, S. S. (in press). Creativity as a matter of choice: Prior experience and task instruction as boundary conditions for the positive effect of choice on creativity. Journal of Creative Behavior. 
Connolly, T., Routhieaux, R. L., \& Schneider, S. K. (1993). On the effectiveness of group brainstorming: Test of one underlying cognitive mechanism. Small Group Research, 24(4), 490-503.

Coskun, H. (2005). Cognitive stimulation with convergent and divergent thinking exercises in brainwriting: Incubation, sequence priming and group context. Small Group Research, $36(4), 466-498$.

Coskun, H., Paulus, P. B., Brown, V., \& Sherwood, J. J. (2000). Cognitive stimulation and problem presentation in idea generation groups. Group Dynamics: Theory, Research, and Practice, 4 , 307-329.

De Bono, E. (1968). New think; the use of lateral thinking in the generation of new ideas. New York, Basic Books.

De Bono, E. (1969). The mechanism of mind. New York, Simon and Schuster.

DeRosa, D. M., Smith, C. L., Hantula, D. A. (2007). The medium matters: Mining the longpromised merit of group interaction in creative idea generation tasks in a meta-analysis of the electronic group brainstorming literature. Computers in Human Behavior, 23, 15491581.

Dennis, A. R., \& Williams, M. L. (2003). Electronic brainstorming: Theory research and future directions. In Paulus, P. B. \& Nijstad, B. A. (Eds.), Group creativity: innovation through collaboration (pp. 160-178). Oxford University Press, California.

Dennis, A., Aronson, J., Heninger, B., \& Walker, E. (1996). Task and time decomposition in electronic brainstorming. Proceedings of HICSS, 11, 51-59.

Dennis, A., Valacich, J. S., Connolly, T., \& Wynne, B. E. (1996). Process structuring in electronic brainstorming. Information Systems Research, 7, 268-277. 
Diehl, M., \& Stroebe, W. (1987). Productivity loss in brainstorming groups: Towards the solution of a riddle. Journal of Personality and Social Psychology, 53, 497-509.

Diehl, M. (1991). Kollektive Kreativität: Zur Quantität und Qualität der Ideenproduktion in Kleingruppen (Collective creativity: On quantity and quality of idea production in small groups). Germany: Habilitationschrift, University of Tübingen.

Diehl, M., \& Stroebe, W. (1991). Productivity loss in idea idea-generating groups: Tracking down the blocking effect. Journal of Personality and Social Psychology, 61(3), 392-403.

Dugosh, K. L., \& Paulus, P. B. (2005). Cognitive and social comparison processes in brainstorming. Journal of Experimental Social Psychology, 41, 313-320.

Dugosh, K. L., Paulus, P. B., Roland, E. J. \& Yang, H. (2000). Cognitive Stimulation in Brainstorming. Journal of Personality and Social Psychology, 79 (5), 722-735.

Dunbar K. (1997). How scientists think: On-line creativity and conceptual change in science. In T. B. Ward, S. M. Smith, \& J. Vaid (Eds.), Creative thought: An investigation of conceptual structures and processes (pp. 461-493). Washington DC: American Psychological Association.

Dunbar, K. (1995). How scientists really reason: Scientific reasoning in real world laboratories. In R. J. Sternberg \& J. E. Davidson (Eds.). The nature of insight (pp. 365-395). Cambridge, MA: MIT Press.

Engelmann, P. D., \& Gettys, C. F. (1985). Divergent thinking in act generation. Acta Psychologica, 60(1), 39-56.

Eisenberger, R. \& Armeli, S. (1997). Can salient reward increase creative performance without reducing intrinsic creativity interest? Journal of Personality and Social Psychology, $72(3), 652-663$. 
Gallupe, R. B., Bastianutti, L. M., \& Copper, W. H. (1991).Unblocking brainstorms. Journal of Applied Psychology. 76,137-142.

Gallupe, R. B., Copper, W. H., Grisé, M. L. \& Bastianutti, L. M., (1994).Blocking electronic brainstorms. Journal of Applied Psychology. 79,77-86.

Garfield, M. J., Taylor, N. J., Dennis, A. R., \& Satzinger, J. W. (2001).Research report: Modifying paradigms- individual differences, creativity, techniques, and exposure to ideas in group idea generation. Information Systems Research, 12(3), 322-333.

Gettys, C. F., Pliske, R. M., \& Manning, C. (1987). An evaluation of human act generation performance. Organizational Behavior and Human Decision Processes. 39(1), 23-51.

Goldenberg, J., Mazursky, D., \& Solomon S. (1999a). Toward identifying the inventive templates of new products: A channeled ideation approach, Journal of Marketing Research, 36(2), 200-210.

Goldenberg, J., Mazursky, D., \& Solomon S. (1999b). Creative sparks. Science, 285 (5433), 1495-1496.

Harkins, S. G. \& Petty, R. E. (1982). Effects of task difficulty and task uniqueness on social loafing. Journal of Personality and Social Psychology, 43(6), 1214-1229.

Hender, J. M., Dean, D. L., Rodgers, T. L. \& Nunamaker, J. F. (2002). An examination of the impact of stimuli type and GSS structure on creativity. Brainstorming versus nonbrainstorming techniques in a GSS environment. Journal of Management Systems, 18, 59-85.

Hinsz, V. B., Tindale, R. S. \& Vollrath, D. A. (1997). The emerging conceptualization of groups as information processes. Psychological Bulletin, 121(1), 43-64.

Hollingshead, A. B. (1998a). Retrieval process in transactive memory systems. Journal of 
Personality and Social Psychology, 74 (3), 659-671.

Hollingshead, A. B. (1998b). Distributed knowledge and transactive processes in decisionmaking groups. In, Gruenfeld, Deborah H. (Ed.), Composition. US: Elsevier Science/JAI Press, 103-123.

Hollingshead, A. B. (2000). Perceptions of expertise and transactive memory in work relationships. Group Processes and Intergroup relations, 3, 257-267.

Hollingshead, A. B. (2001). Cognitive interdependence and convergent expectations in transactive memory. Journal of Personality and Social Psychology, 81 (6), 1080-1089.

Janis, I. L. (1972). Victims of groupthink: A psychological study of foreign-policy decisions and fiascoes. Oxford, England: Houghton Mifflin.

Johnson, D. W. \& Johnson, R. (1989). Cooperation and Competition, Theory and Research. Edina, MN.

Johnson, D. W. \& Johnson, R. (1999). Making cooperative learning work, Theory into Practice, 38 , (2) 67-74.

Johnson, D. W., Johnson, R. T., \& Stanne, M. B. (1989). Impact of goal and resource interdependence on problem-solving success. Journal of Social Psychology, 129(5), 621629.

Kramer, M. W., Fleming, G. P., \& Mannis, S. M. (2001). Improving face-to-face brainstorming through modeling and facilitation. Small Group Research, 32(5), 533-557.

Lamm, H. \& Trommsdorff, G. (1973). Group versus individual performance on a task requiring ideational proficiency (brainstorming): A review. European Journal of Social Psychology, 3,362-388. 
Larey, T. S. \& Paulus, P. B. (1999). Group preference and convergent tendencies in small groups: A content analysis of group brainstorming performance. Creativity Research Journal, 12(3), 175-184.

Littlepage, G. E., Robison, W. \& Reddington, K. (1997). Effects of task experience and group experience on group performance, member ability, and recognition of expertise. Organizational Behavior and Human Decision Processes, 69(2), 133-147.

MacCrimmon, K., \& Wagner, C. (1994). Stimulating ideas through creativity software. Management Science, 40(11), 1514-1532.

Maier, N. R. (1967). Assets and liabilities in group problem solving: The need for an integrative function. Psychological Review. 74(4), 239-249.

Mobley, M. I., Doares, L. M., \& Mumford, M. D. (1992). Process analytic models of creative capacities: Evidence for the combination and reorganization process. Creativity Research Journal, 5(2), 125-155.

Moreland, R. L., Argote, L., \& Krishnan, R. (1996). Social shared cognition at work: transactive memory and group performance. In J. L. Nye \& a. M. Brower (Eds.), What social about social cognition? Research on socially shared cognition in small groups (pp. 57-84).

Thousand Oaks, CA: Sage.

Mullen, B., Johnson, C., \& Salas, E. (1991). Productivity loss in brainstorming groups: A metaanalytic integration. Basic and Applied Social Psychology, 12, 3-24.

Mumford, M. D. \& Gustafson, S. B. (1988). Creativity syndrome: Integration, application, and innovation. Psychological Bulletin, 103(1), 27-43.

Nagasundaram, M., \& Dennis, A. R. (1993). When a group is not a group: The cognitive foundation of group idea generation. Small Group Research, 24, 463-489. 
Nakui, T. (2006).The effects of attitude toward diverse workgroups on diverse brainstorming groups. Dissertation Abstract International. 130.

Nemeth, C. J., \& Nemeth-Brown, B. (2003). Better than individuals? The potential benefits of dissent and diversity for group creativity. In: Paulus, P. B.; Nijstad, B. A (Eds.), Group creativity: Innovation through collaboration (pp. 63-84.) New York, NY, US: Oxford University Press.

Nijstad. B. A., \& Stroebe, W. (2006). How the group affects the mind: A cognitive model of idea generation in groups. Personality and Social Psychology Review, 10(3), 186-213.

Nijstad, B. A., Stroebe, W., \& Lodewijkx, H. F. M. (1999). Persistence of brainstorming groups: How do people know when to stop? Journal of Experimental Social. 35, 165-185.

Nijstad. B. A., Stroebe, W., \& Lodewijkx, F. M. (2002). Cognitive stimulation and interference in groups: Exposure effects in an idea generation task. Journal of Experimental Social Psychology, 38, 534-544.

Offner A.K., Kramer, T. J., \& Winter, J. P. (1996). The effects of facilitation, recording and pauses on group brainstorming. Small Group Research 27, 283-298

Osborn, A. F. (1957). Applied imaginations ( $1^{\text {st }}$ Ed.). New York: Scribner.

Paulus, P. B., \& Brown, V. R. (2007). Toward more creative and innovative group idea generation: A cognitive-social motivational perspective of brainstorming. Social and Personality Compass, 1, 10:1111/j.1751-9004.2007.00006.x

Paulus, P. B., \& Dzindolet, M. T. (1993). Social influence processes in group brainstorming. Journal of Personality and Social Psychology, 64, 575-586.

Paulus, P. B., Nakui, T. \& Putman, V. L (2006). Effects of task instruction and brief breaks on brainstorming. Group Dynamics: Theory, Research and Practice, 10(3), 206-219. 
Pelz, D. C., \& Andrews, F. M. (1966). Scientists in organizations: Productive climates for research and development. Oxford, England: John Wiley, 318 pp.

Pinsonneault, A., Barki, H., Gallupe, R. B., \& Hoppen, N. (1999). Electronic brainstorming: the illusion of productivity. Information Systems Research, 10, 110-133.

Pissarra, J. \& Jesuino, J. C. Idea generation through computer-mediated communication: The effects of anonymity. Journal of Managerial Psychology, 20, 275-291

Pitz, G. F., Sachs, N. J., \& Heerboth, J. (1980). Procedures for eliciting choices in the analysis of individual decisions. Organizational Behavior and Human Performance, 26(3). 396-408.

Proctor R. A. (1993). Computer stimulated associations. Creative Research Journal, 6(4) 391400.

Putman, V. L., \& Paulus, P. B. (2007). Brainstorming, brainstorming rules and decision making. Journal of Creative Behavior.

Rietzschel, E. F., Nijstad, B. A. \& Stroebe, W. (2006). Productivity is not enough: A comparison of interactive and nominal brainstorming groups on idea generation and selection. Journal of Experimental Social Psychology, 42, 244-251.

Rietzschel, E. F., Nijstad, B. A. \& Stroebe, W. (2007). Relative accessibility of domain knowledge and creativity: The effects of knowledge activation on the quantity and originality of generated ideas. Journal of Experimental Social Psychology, 43, 933-946.

Roenker, D. L., Thompson, C. P. \& Brown, S.C. (1971). Comparison of measures for the estimation of clustering in free recall. Psychological Bulletin, 76 (1), 45-48.

Sherwood, J. (1998). Modeling cognitive facilitation in brainstorming groups. Unpublished master's thesis, University of Texas at Arlington. 
Smith, S. M. (2003). The constraining effects of initial ideas. In P. B. Paulus \& B. A. Nijstad (Eds.), Group creativity (pp. 15-31). New York: Oxford University Press.

Stasser, G. \& Titus, W. (1985). Pooling of unshared information in group decision-making: Biased information sampling during discussion. Journal of Personality and Social Psychology, 48(6), 1985.

Stewart, D. D., Billings, R. S. \& Stasser, G. (1998). Accountability and the discussion of unshared, critical information in decision-making groups. Group Dynamics: Theory, Research, and Practice, 2(1), 18-23.

Stewart, D. D., Wittenbaum, G. W., \& Stasser, G. (1995). Expert roles and information exchange during discussion: The importance of knowing who knows what. Journal of Experimental Social Psychology, 31(3), 244-265.

Taylor, D. W., Berry, P. C. \& Block, C. H. (1958). Does group participation when using brainstorming facilitate or inhibit creative thinking. Administrative Science Quarterly, 3, $23-47$.

van Knippenberg D., De Drue, C. K. W., \& Homan, A. C. (2004). Work group diversity and group performance: An integrative model and research agenda. Journal of Applied Psychology, 89(6), 1008-1022.

van Knippenberg, D., \& Schippers, M .C. (2007). Work group diversity. Annual Review of Psychology, 58, 515-541.

Vroom, V. H.; Grant, L. D. \& Cotton, T. S. (1969). The consequences of social interaction in group problem solving. Organizational Behavior \& Human Performance, 4(1), 77-95.

Wanous, J. \& Youtz, M. (1986). Solution diversity and the quality of group decisions. Academy of Management Journal, 29(1), 149-158. 
Wegner, D. M. (1987). Transactive memory: Contemporary analysis of the group mind. In B. Mullen \& G. R. Goethals (Eds.), Theories of group behavior (pp. 185-208). New York: Springer-Verlag.

Wegner, D. M. (1995). A computer network model of human transactive memory. Social Cognition, 13(3), 319-339.

Weldon, M. S., \& Bellinger, K. D. (1997). Collective memory: Collaborative and individual processes in remembering. Journal of Experimental Psychology: Learning, Memory, and Cognition. 23(5), 1160-1175.

Wittenbaum, G.M., Hubbell, A.P., Zuckerman, C. (1999). Mutual enhancement: Toward an understanding of the collective preference for shared information. Journal of Personality and Social Psychology, 77(5), 967-978.

Ziegler, R., Diehl, M. \& Zijlstra, G. (2000). Idea production in nominal and virtual groups: Does computer-mediated communication improve group brainstorming? Group Processes and Intergroup Relations, 3,141-158. 


\section{BIOGRAPHICAL INFORMATION}

Jonali Baruah is a research scientist in the UT School of Public Health Dallas Regional Campus at UT Southwestern Medical Center. She has completed her PhD in experimental psychology in the University of Texas at Arlington. Her research seeks to understand the cognitive mechanism that contributes to the creativity of groups. How does it vary in diverse and dispersed groups? How to improve the performance of such groups? 